\title{
CHAPTER 3.7.
}

\section{MONITORING STERILE AND WILD INSECTS IN AREA-WIDE INTEGRATED PEST MANAGEMENT PROGRAMMES}

\author{
M. J. B. VREYSEN \\ Joint FAO/IAEA Division of Nuclear Techniques in Food and Agriculture, \\ International Atomic Energy Agency, A-1400 Vienna, Austria \\ Email:M.Vreysen@iaea.org
}

TABLE OF CONTENTS

1. INTRODUCTION

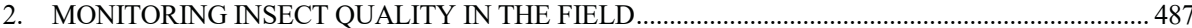

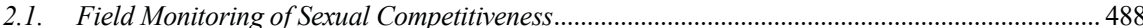

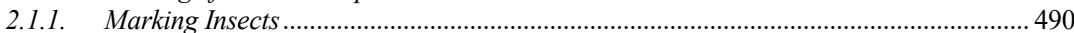

2.2. Field Monitoring of Parameters Related to Sexual Competitiveness ............................................ 493

2.2.1. Apparent Density and Survival ......................................................... 493

2.2.2. Mobility, Dispersal and Distance between Isolated Populations................................. 494

2.2.3. Spatial Distribution within Habitat............................................................................. 496

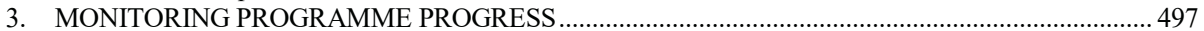

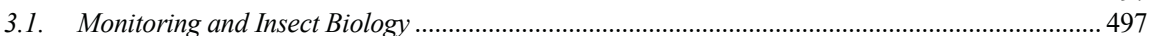

3.1.1. Monitoring and Insect Behaviour ........................................................................... 497

3.1.2. Direct Sampling of Adult Insects.................................................................................. 498

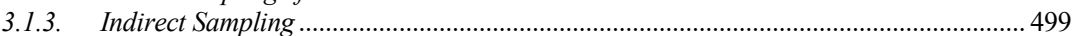

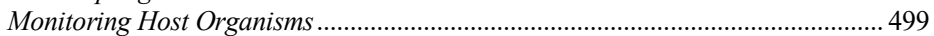

Monitoring Disease Transmission ........................................................................ 500

Monitoring Crop Damage .................................................................... 501

3.2. Monitoring Impact of Sterile Insect Releases on a Wild Population ………………...................... 501

3.2.1. Monitoring Reproductive Capacity of a Wild Population - Tsetse Flies ...................... 503

3.2.2. Monitoring Reproductive Capacity of a Wild Population - Screwworms,

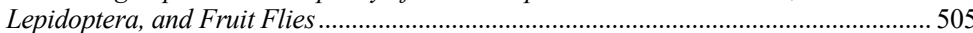

Induced Sterility and Egg Collection.................................................................... 507

Problems Associated with Trapping Female Lepidoptera ……….......................... 508

Distinguishing $F_{1}$ Males from Wild Males in Inherited Sterility Programmes of Lepidoptera

Pages 485-528

V. A. Dyck, J. Hendrichs and A. S. Robinson (eds.), Sterile Insect Technique. Principles and Practice in Area-Wide Integrated Pest Management. Second Edition.

(C) 2021 IAEA. CRC Press, Boca Raton, Florida, USA. 
3.2.3. $\quad$ Monitoring Variations in Age Structure of a Wild Population ...................................... 510

3.2.4. Monitoring Relative Abundance of a Wild Population ..................................................... 512

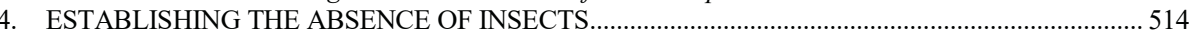

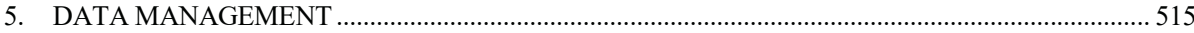

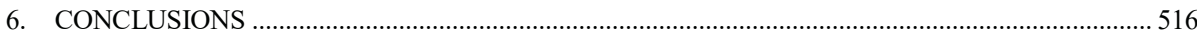

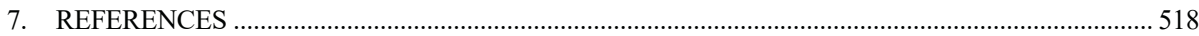

\section{SUMMARY}

Insect pest control programmes, which integrate the release of sterile insects, can be efficient only if the released insects have an optimal biological quality. Frequent monitoring of the quality of reared insects after being released in the field is an important but often neglected component of area-wide integrated pest management (AW-IPM) programmes that integrate the sterile insect technique (SIT). Parameters of sterile insects, which should be monitored regularly, are sexual competitiveness of the released insects, and related components, e.g. survival, mobility, dispersal characteristics, and spatial occupation of the habitat. A wellbalanced monitoring programme will, at any given time, provide essential feedback on the target and sterile populations in the field, and therefore on whether progress is being made. This information is prerequisite to efficient implementation of the release and cost-efficient use of sterile insects. The type of monitoring to be done will be determined largely by the particular biology of the target insect species. The rate of sterility induced in the wild insect pest population is the most important parameter in relation to the release of sterile insects; an increased rate of induced sterility in the native female population can unequivocally be linked to a decrease in the density of the target insect population.

\section{INTRODUCTION}

Successful area-wide integrated pest management (AW-IPM) programmes using the sterile insect technique (SIT) against insect pests require reliable data on the biology of the target insect, especially its sexual behaviour, population dynamics, and temporal and spatial fluctuations in population density and distribution (Itô et al., this volume). This information is essential to accurately interpret data accumulated during the monitoring of a programme. Monitoring sterile and wild insects is a critical aspect of any SIT operation and includes: (1) the performance of sterile insects after release, and (2) the impact of sterile males and other control tactics on the wild target population.

The efficient implementation and success of any control programme using the SIT will depend on factors related directly to the quality of the released insects (Parker, Vreysen et al., this volume). It is imperative that the released sterile insects intermingle rapidly with the wild population after being released, and mate at the same rate as the wild insects. The production of insects in a rearing facility, that have a "biological quality" or "competitiveness" comparable with that of wild insects, is much more complicated than might be anticipated. This quality can easily be impaired due to: (1) aspects inherent to the colonization and mass-rearing procedures (artificial environment, holding density, stress) (Parker, Mamai et al., this volume), (2) the sterilization treatment with ionizing radiation (Bakri et al., this volume), (3) the physical handling and marking procedures at the production or release centres, and (4) the transport of the insects to the release site (Dowell et al., this volume; Parker, Mamai et al., this volume; Parker, Vreysen et al., this volume). In addition, the behaviour of the reared and released insects could be altered drastically due to changes induced in the genetic traits of the mother stock kept for numerous generations under artificial conditions. Continuous rearing may select for traits that favour mass- 
production (early maturation, high fecundity, mating at high densities), but which could negatively affect field performance (courtship behaviour, release of pheromones, territorial behaviour) and even prevent released insects from mating with wild insects (Lance and McInnis, this volume).

Ideally, to assure optimal quality of reared insects, rigorous quality control procedures must be implemented at all times and in all phases of production, not only on an ad hoc basis or after the emergence of a problem (Spradbery 1994). However, regardless of how meticulously quality control procedures are implemented, the laboratory criteria of fitness may have little bearing on the ability of released males to survive and mate with wild females (Krafsur and Hightower 1979). Admittedly, measurement of the "biological quality" of sterile insects in a laboratory or field cage is a convenient way to assess the effect of several factors related to sexual competitiveness (FAO/IAEA/USDA 2019; Parker, Vreysen et al., this volume), but it does not assess other parameters that are also of relevance to the insect's performance in the open field. Therefore, the frequent monitoring of the competitiveness of the released insects and related parameters, such as survival, dispersal rate, and spatial occupation in the natural habitat, is an indispensable component of AW-IPM programmes that integrate the release of sterile insects.

Efficient programme implementation and technical management of an AW-IPM programme are only possible through the regular and frequent analysis of accurately collected field data. In practice, not all programmes using the SIT grant the same importance to monitoring and data analysis, and the emphasis given depends on factors such as: (1) level of experience of the managers, and their confidence in the programme, (2) economics and availability of sterile insects (is it cheaper to release more insects than develop an extensive monitoring programme?), and (3) efficiency and economics of the available monitoring tools. Scientifically sound monitoring activities require significant funding for personnel, equipment, logistics, and recurrent expenses, and as a consequence, insufficient importance is often given to this component. However, when progress does not match expectations, accurate field data are a prerequisite to detecting the causes of the problem and applying corrective measures. Otherwise, programme managers are doomed to "guess work" and making decisions based on assumptions, frequently resulting in technical and financial failure.

History teaches us that any AW-IPM programme will face external criticism, especially when the goal of the programme is to eradicate the target insect population in a circumscribed area (Klassen and Vreysen, this volume). Unfortunately, it is usually the uninformed "outsider", lacking appropriate scientific background or insight into the activities and challenges being faced by the programme, who is criticizing it. A scientifically sound monitoring programme is an essential element in successfully refuting such criticism.

\section{MONITORING INSECT QUALITY IN THE FIELD}

Surprisingly little attention has been given to monitoring the competitiveness of sterile insects in the field. In part, this is due to the technical difficulties involved in making these types of observations. In recent years, however, significant progress has been made by using larger walk-in field cages to study a set of parameters (e.g. preferred 
host location, courtship and mating behaviour, mating compatibility, spatial distribution related to female location, mating success, etc.) that are relevant to the sexual competitiveness of the reared sterile insects in a semi-controlled natural environment (FAO/IAEA/USDA 2019; Parker, Vreysen et al., this volume). Even with this important development, the successful interaction of mass-reared sterile males with wild females in the field is still the key to the success of the SIT, and every effort should be made to assess the extent of this interaction. A Field Quality Control group, that designs a set of tests tailored to the needs of a target species, must be an essential part of all field programmes. This group should be composed of full-time employees of the programme who have the required expertise in conducting field evaluations, and extensive knowledge about the ecology and behaviour of the target insect (FAO/IAEA/USDA 2019).

\subsection{Field Monitoring of Sexual Competitiveness}

The competitiveness of an organism is defined as its ability to compete with conspecific organisms for a limited environmental resource (FAO/IAEA/USDA 2019). Fitness in wild insects involves their genetic contribution to the next generation's gene pool relative to the average for the population. Sterile insects do not reproduce, and therefore do not contribute to the next generation's gene pool. Their competitiveness is largely a matter of survival, dispersion (spatial occupation of the habitat), adequate behavioural responses, habitat finding, and successful mating, i.e. it ends with mating or insemination (LaChance 1979). Therefore, the general sexual competitiveness of a sterile insect is largely defined and influenced by components such as survival, mating propensity, mating compatibility, post-mating factors, etc. (FAO/IAEA/USDA 2019; Lance and McInnis, this volume). In view of the drastic changes, due to continued mass-rearing, that can be induced in the genetic traits of reared insects, the frequent measurement of sexual competitiveness and its related components under field conditions is indispensable for success (Haisch 1970; Itô and Koyama 1982).

The sexual competitiveness ' $c$ ' of sterile insects was defined by Fried (1971), and its value will normally fluctuate between 0 and 1 (Itô and Koyama 1982; Iwahashi et al. 1983; Itô et al., this volume). The importance of regularly monitoring the sexual competitiveness in the field was demonstrated in the programme against the melon fly Zeugodacus cucurbitae (Coquillett) on Kume Island, Japan. In the beginning of the release programme, mating competitiveness measured in the field was high $(c=0.8)$, and comparable with that obtained in laboratory cage tests. After 18 generations of continuous mass-rearing, the field value of $c$ dropped to 0.2 , whereas the laboratory value remained high. This difference was attributed to the inferior mating performance of wild males in small laboratory cages, and a real decline in the field competitiveness of sterile males due to rearing-induced genetic changes, i.e. domestication, and the development of SIT resistance in the wild population (Iwahashi et al. 1983; Lance and McInnis, this volume; Whitten and Mahon, this volume). As a result of monitoring the field $c$ value, programme managers were alerted, took corrective action in a timely manner, and the melon fly was eradicated in Kume Island. 
An interesting trend in the field competitiveness of released insects, in relation to the operational size of an AW-IPM programme, is provided by the New World screwworm Cochliomyia hominivorax (Coquerel) eradication programme in the USA and Central America. In the first decade of the programme in the USA (Curaçao, Florida, Texas 1954-1962) (Klassen et al., this volume), less than 50 million sterile insects per week were released at low densities, and competitiveness was 0.29-0.43. However, when production increased to 500 million sterile insects per week, the competitiveness dropped to below 0.1 (Mayer et al. 1998), indicating that increased production levels have a negative impact on field competitiveness. Measures such as regularly renewing the strains when the programme moved from the arid south USA to tropical Central America mitigated the problem.

Fried's model indicates that the sexual competitiveness of released insects is inherently linked to the sterile to wild insect ratio obtained in the field. Calculations of critical sterile to wild ratios for any target insect (Barclay, this volume) are usually based on experience or the results of mathematical models, and may vary considerably among insect species, and between theory (models) and practice (operational programmes). Critical sterile to wild ratios varied between 7:1 for the tsetse fly Glossina palpalis gambiensis Vanderplank (Politzar and Cuisance 1984), 25:1 for the olive fruit fly Bactrocera oleae (Gmelin) (Tzanakakis 1974), 40:1 for the codling moth Cydia pomonella (L.) (Dyck et al. 1993), 60:1 for the pink bollworm Pectinophora gossypiella (Saunders) (Staten et al. 1993), 80:1 for the Mediterranean fruit fly Ceratitis capitata (Wiedemann) (Villaseñor et al. 2000), and 25-100:1 for the New World screwworm (J. W. Snow, personal communication). Operational sterile to wild ratios can even be different for species and subspecies within a genus, e.g. a sterile to wild male ratio of 7-10:1, greater than 10:1, and greater than 30:1, was applied against $G$. palpalis gambiensis in Burkina Faso, Glossina palpalis palpalis Robineau-Desvoidy in Nigeria, and Glossina austeni Newstead in Unguja Island, Zanzibar, respectively (Politzar and Cuisance 1984; Oladunmade et al. 1990; Vreysen et al. 2000). Most likely these differences are related to distinct ecological affinities of the target insect, their mobility, spatial occupation of the habitat, population regulation, sterile male quality, etc.

Even though the critical ratio of sterile to wild males for a target insect can be influenced by factors such as the reproductive potential of the females, climatic conditions, biological quality of the insects before leaving the rearing facility, funds available to disperse sterile insects, and time available to achieve suppression or eradication, it is the true density and distribution of the wild insect population that is the most determining factor. The number of wild insects per unit of habitat surface determines the release rate of sterile insects that is required to achieve the desired sterile to wild ratio in the target area. In turn, the production capacity of the rearing facility must be adequate for the chosen release rate. Underestimating the actual population density can result in a shortage of available sterile insects in the production facility, whereas overestimating it will lead to overproduction and unnecessarily increased costs (Bloem and Bloem 2000). The density of insect populations is usually strongly correlated with habitat and vegetation cover, e.g. melon fly density in Okinawa, Japan, varied from less than 10 flies per hectare in the mountains to greater than 600 flies per hectare in crop fields and bushy areas (Yamagishi et al. 1993). 
Therefore, the density in all vegetation types in the target area should be estimated so as to adjust accordingly the number of sterile males released. It is important that the critical sterile to wild ratio be obtained in all trap sites, indicating that sterile insects have been appropriately placed in the target area (Krafsur et al. 1980). Several simple mathematical models are available to assess absolute insect population densities, e.g. Lincoln Index (Southwood 1978), and Jackson's positive and negative method (Jackson 1939), but these methods have rarely been routinely used in operational programmes integrating the SIT (Itô et al., this volume).

The patchy distribution of most insect species (Itô et al., this volume; Lance and McInnis, this volume), and the strong correlation between insect density and vegetation type, has implications for interpreting "overflooding ratios" when releasing sterile insects, i.e. one should take into account not only the overall sterile to wild male ratio obtained in all traps in a given area over a period of time, but also the ratios achieved in each type of habitat and vegetation cover must be adequate. Therefore, a suitable network of traps, strategically deployed in all habitats, is needed (Vreysen et al. 2000).

\subsubsection{Marking Insects}

To calculate sterile to wild ratios, sterile insects are usually marked before release (FAO/OIEA 2018; Dowell et al., this volume; Parker, Mamai et al., this volume). Marking is traditionally done using physical markers (e.g. fluorescent dye on the entire body, acrylic paint on the thorax (for small pilot trials) or Calco Red in the diet of some Lepidoptera), but some of these markers have issues of cost, human health, sustainability or negative effects on the insects' competitiveness (Hagler and Jackson 2001; Parker, Mamai et al., this volume). More stable morphological markers have become available, such as the VIENNA 8-Sergeant $\left(\mathrm{Sr}^{2}\right)$ strain of the Mediterranean fruit fly, that in addition to the temperature sensitive lethal ( $t s l$ ) and white pupae ( $w p$ ) mutations, carries the dominant Sergeant $2\left(\mathrm{Sr}^{2}\right)$ mutation that is expressed in males as three abdominal stripes, whereas wild-type males have only two stripes (Nyazi et al. 2005). The transgenic strain VIENNA 8-1260 presents another stable marker for the Mediterranean fruit fly. The strain expresses the Ccb2t promotor driver tGFP in the testes as green fluorescence and DsRed in the body as red fluorescence (Scolari et al. 2008) (Fig. 1).

Irrespective of which marker is being used, it needs to be ascertained whether there are negative effects on production in the mass-rearing facility or on their sexual competitiveness, survival, dispersal, etc. In that respect, Rempoulakis et al. (2016) assessed production parameters and competitiveness of the above-mentioned Mediterranean fruit fly strains in walk-in field cages. VIENNA 8-1260 females produced fewer eggs than the other two strains, but the egg hatch of all strains was similar. Differences in male mating competitiveness of the three strains against wildtype males were gradually reduced with successive generations under semi massrearing conditions. However, VIENNA 8 males adapted faster to laboratory conditions as compared with VIENNA 8-Sr${ }^{2}$ and VIENNA 8-1260 males with respect to mating competitiveness. VIENNA 8 males of the $F_{10}$ generation were equally competitive with wild-type males, whereas the mating competitiveness of VIENNA $8-S r^{2}$ and 
VIENNA 8-1260 males was similar but lower as compared with wild-type males. Males from all three strains copulated earlier than wild-type males.

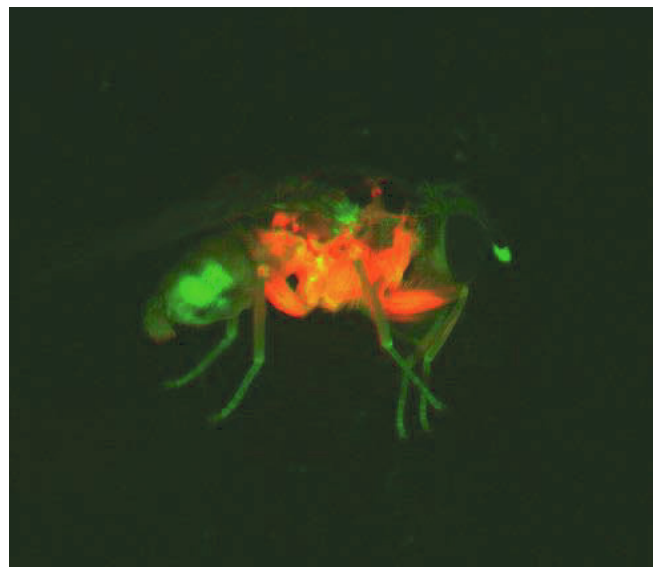

Figure 1. Mediterranean fruit fly strain VIENNA 8-1260 expressing green fluorescence in the testes and red fluorescence in the body. (Photo from G. Franz, reproduced with permission.)

Recently, the biomarker dye rhodamine B has shown promise as a marker for Lepidoptera and mosquitoes. Feeding male tobacco budworm Heliothis virescens $(\mathrm{F}$.) on $0.1 \%$ rhodamine dissolved in $10 \%$ sucrose solution did not only stain the body of the males but could also be detected in the spermatophores of female moths that had mated with the males. The intake of the dye had no effect on life span and mating performance of the males and production of eggs (Blanco et al. 2006). Sugar-feeding with rhodamine was used to stain the seminal fluid and bodies of male Aedes aegypti (L.) with no significant impact on their survival or mating competitiveness (Johnson et al. 2017).

In programmes releasing sterile New World screwworms, the flies are not marked, and estimations of the ratio of sterile to wild insects are based on catches of female insects. Females are dissected, and the atrophied ovaries of sterile females distinguish them from wild females. However, caution is required in interpreting these data. Sterile to wild ratios are derived from trapped insects, and if the distribution and response to traps is different for sterile and wild male insects, the ratios are prone to error (Meats 1996). One must also be cautious in interpreting female screwworm ratios; they might not reflect actual male screwworm ratios in the field due to sexrelated differences in longevity, response to the trapping device, and dispersal characteristics.

Insects may be trapped in areas where their presence is not expected or anticipated, or where it is paramount to know their origin, e.g. in pest free areas, in recently cleared areas, in traps that are deployed in the vicinity of mass-rearing facilities, or an unmarked insect trapped at the end of an eradication campaign that potentially has lost 
its physical marker. In all these cases there is a need to identify the origin of the insect, or whether the insect is a sterile released or a wild relic fly. For some insect species, such as the Mediterranean fruit fly, molecular markers have become available that allow an assessment of the origin of the trapped flies (Meixner et al. 2002; Silva et al. 2003). The use of release strains that differ in their mtDNA background from that of the target population facilitates discriminating between unmarked flies and new incursions into a free area (San Andres et al. 2007; Franz et al., this volume).

Similarly, a molecular technique has been developed, based on the determination of cytochrome oxidase haplotypes to discriminate between wild and sterile male tsetse flies Glossina palpalis gambiensis with a high level of accuracy. The DNA was isolated from the heads of flies and a portion of the $5^{\prime}$ end of the mitochondrial gene cytochrome oxidase I was amplified for sequencing. All sterile male flies from a Burkina Faso strain had the same haplotype but differed from that of wild male flies trapped in Senegal and in Burkina Faso. The method allows 100\% discrimination between sterile and wild male G. p. gambiensis and can be used in release programmes in case there is doubt regarding the origin of a trapped fly (Pagabeleguem et al. 2016).

Stable isotopes have been used successfully to determine the natal origin of insects, their feeding strategies and mating behaviour (IAEA 2009; Vreysen et al. 2016). Enriching the water in which larvae of the mosquito Culex pipiens L. (Diptera: Culicidae) developed with ${ }^{15} \mathrm{~N}$-labeled potassium nitrate and ${ }^{13} \mathrm{C}$-labelled glucose allowed the differentiation of marked from unmarked adult mosquitoes throughout their entire lifespans, e.g. 55 days. The labelling had no effect on immature mosquito survival or adult body size, and the technique was also applied to mark naturally breeding mosquitoes in standing water bodies in the field (Hamer et al. 2012). HoodNowotny et al. (2016a) labelled seven species of lepidopterans: cactus moth Cactoblastis cactorum (Berg), Eldana saccharina Walker, Spodoptera litura (F.), Epiphyas postvittana (Walker), diamondback moth Plutella xylostella (L.), Lobesia botrana (Denis and Schiffermüller), and pink bollworm Pectinophora gossypiella (Saunders), which made them distinguishable from wild conspecific moths based primarily on the difference in the ratio of the stable isotopes ${ }^{13} \mathrm{C}:{ }^{12} \mathrm{C}$. Depending on whether the wild host plants had a $\mathrm{C} 3$ or $\mathrm{C} 4$ metabolism, the diets were prepared with sugar derived either from sugarcane or sugar beet, so that the moths reared on the meridic diet had a ratio different from wild moths. The technique also worked with the tsetse fly Glossina pallidipes (Austen); laboratory-reared flies remained distinguishable from wild flies for more than 80 days (Hood-Nowotny et al. 2011). Mass-reared Mediterranean fruit flies fed on a larval diet containing C4 sugar could be distinguished with $>95 \%$ confidence from wild flies that had developed mostly within the fruits of $\mathrm{C} 3$ plants. The $\mathrm{C} 4$ marker was detectable up to 12 days after release (Hood-Nowotny et al. 2009).

Elemental analysis-isotope ratio mass spectrometry (EA-IRMS) is the standard tool to measure isotope signatures, but this technology is expensive. A simpler technology called combustion module-cavity ring-down spectroscopy (CM-CRDS) is now available on the market. The technology is cheaper and more convenient than EA-IRMS, and data obtained were in good agreement with those obtained using EAIRMS in terms of accuracy and precision (Hood-Nowotny et al. 2016b). 


\subsection{Field Monitoring of Parameters Related to Sexual Competitiveness}

\subsubsection{Apparent Density and Survival}

In routine monitoring, the most immediately available parameter is the proportion of sterile insects recaptured within a certain time frame, i.e. the recapture rate, and a sudden decrease in this rate could reflect a change in the quality of the released insect or in distribution methods (Hutt 1979; Yamagishi et al. 1993).

To increase their chances of encountering a receptive virgin female, sterile males need to survive and have a sexually active life in the field for as long as possible (Curtis and Langley 1982). It is important to estimate this parameter and investigate methods to increase the survival (longevity) of released sterile males (Lance and McInnis, this volume; Parker, Vreysen et al., this volume). After leaving a rearing facility, released sterile insects must find a food source or a host to replenish their limited energy reserves. In the absence of a host, their life expectancy is determined by the available initial energy reserves and the post-factory treatments before release (Pereira et al., this volume). Therefore, it is a critical parameter, and can be assessed in the laboratory (FAO 1992) or in field cages under natural conditions (Vreysen 1995).

An exponential decline in the recapture rate of marked released insects gives an indication of the daily survival (or mortality) rate in the area (Fig. 2). The survival rates will determine the frequency of sterile insect releases, ensuring appropriate sterile male densities over the entire target area at all times (Dowell et al., this volume). Sterile insect survival is influenced by factors such as host availability, climatic conditions, predator avoidance capacity, and vegetation cover, and therefore the survival of released insects should be assessed in all seasons and in all representative areas of the target zone.

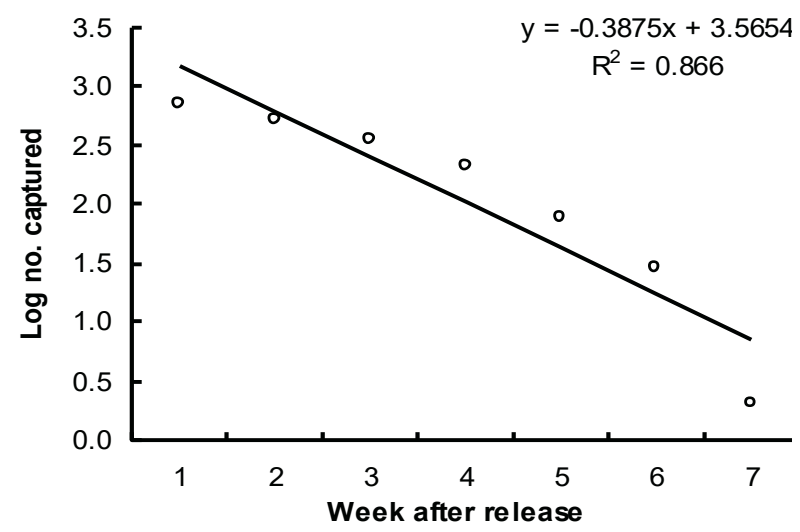

Figure 2. Survival of sterile male Glossina austeni aerially released in Unguja Island, Zanzibar, Tanzania. 


\subsubsection{Mobility, Dispersal and Distance between Isolated Populations}

Released sterile insects need to be sufficiently mobile, and have adequate dispersal capabilities, to reach (in a timely fashion) all the ecological niches occupied by the wild insect population (Itô et al., this volume; Lance and McInnis, this volume). Mobility and the potential of released insects to disperse are often underestimated. The recorded maximum dispersal distance for released New World screwworms is $290 \mathrm{~km}$, $107 \mathrm{~km}$ for melon flies, $48 \mathrm{~km}$ for oriental fruit flies Bactrocera dorsalis (Hendel), and $18.5 \mathrm{~km}$ for the tsetse fly G. p. gambiensis (Hightower et al. 1965; Proverbs 1974; Van der Vloedt et al. 1980). Lance and McInnis (this volume) discuss the implications of this high mobility for programmes using the SIT.

Knowledge about the mobility and dispersal characteristics of released insects is essential for developing and designing appropriate release strategies (Itô et al., this volume). Admittedly, this is complicated; there are many variables that influence the dispersal of insects, e.g. wind direction (Peterson et al. 1980), wind velocity (Parman 1945), vegetation density (Krafsur and Hightower 1979), relative humidity (Brenner 1984), host availability (Spradbery 1994), radiation dose (Cuisance and Itard 1973; Wong et al. 1982), and the release of only males or both sexes (Proverbs et al. 1973; Hendrichs et al. 1995). A release strategy should aim at deploying sterile insects in close proximity to wild virgin females. Release lanes for aerial distribution, or release points for ground release, should be separated by a distance not exceeding the average maximum dispersal distance of the released insect (Dowell et al., this volume). Evidence from New World screwworm programmes suggests that the efficiency of released males, as measured by their mating frequency, is strongly influenced by operational considerations of sterile fly distribution. Distance between parallel flight lanes, and fly density in release containers, are especially critical variables (Krafsur et al. 1980). The sterility of wild populations increased significantly if flies were distributed in small boxes of 400 flies in release swaths of $2 \mathrm{~km}$ instead of in larger boxes of 2000 flies in swaths of $8 \mathrm{~km}$ (Krafsur and Garcia 1978). Obviously a denser network of aerial release lanes will require more aircraft time and is more expensive, but the programme will be more efficient, and releases of sterile insects would possibly be needed for a shorter time period.

The mobility and dispersal capacity of released sterile insects should be monitored frequently and compared with those of wild insects. This will require the capture, marking and release-recapture of large numbers of wild insects, and unfortunately these are not always available. Although in the past several complex mathematical models have been developed that describe the movement and mobility of insect species (Williams et al. 1992), a simple but useful index is the "mean distance of dispersal" from a release site to a trap (Itô and Koyama 1982; FAO/IAEA/USDA 2019):

$$
x=\frac{\sum_{j=1}^{n} x_{j} N_{j}}{\sum_{j=1}^{n} N_{j}}
$$

where $n=$ number of traps, $x_{j}$ is the distance between a release point and the $j$-th trap, and $N_{j}$ is the number of flies recaptured with the $j$-th trap. 
The mean distance of dispersal can easily be measured by deploying traps along a regular grid of at least $6 \times 6$ traps, the dimensions of the grid depending on the insect species. Grids are usually easier to set up than a series of concentric circles, but circles are better for measuring dispersal. Caution is required in selecting the sampling device, and especially in using traps in combination with powerful attractants (e.g. pheromone traps for Lepidoptera), that could mask the natural dispersal characteristics of the insect. For lepidopteran species, passive, non-attractant interception traps are an alternative to male pheromone traps; they have been used to determine natural flight paths and flight patterns of insects in search of mates or hosts. The disadvantage of this technique is that catches are usually very small, making statistical analysis difficult or impossible (Knight 2000).

Caution is likewise required in generalizing results from mark-release-recapture studies (Itô et al., this volume), as these are, in the case of mosquitoes, influenced by the ecological characteristics of the study sites, and these studies should always be made in the area where the mosquito project is being conducted (Petric et al. 2014; FAO/IAEA 2020b).

Dispersal is an important factor to consider when making strategic decisions on the selection of target areas for AW-IPM approaches, be it suppression or eradication (Hendrichs, Vreysen et al., this volume). For example, in the past, estimates of the dispersal capacity of the tsetse fly G. p. gambiensis at the microscale were obtained using direct methods (mark-release-recapture) as well as indirect ones (genetic isolation by distance). In this species, genetic isolation was strongly correlated with distance; however, populations separated by $15 \mathrm{~km}$ of rice plantations were more isolated than those separated by $100 \mathrm{~km}$ of gallery forest, indicating that for this species the friction of riparian vegetation to dispersal was significantly lower than that of rice plantations (Bouyer et al. 2009; De Meeûs et al. 2012). As no useful friction maps were available for tsetse flies at any scale, a friction map was developed to identify natural barriers that isolate populations of G. p. gambiensis in West Africa. A statistical model was used to assess the genetic distance between 37 tsetse populations sampled in West Africa, using a set of remotely sensed environmental data as predictors. The least-cost path between these populations was then estimated using the predicted friction map. The method avoids the subjectivity inherent in expert-based weighting of environmental parameters. As a result, potentially isolated clusters of G. p. gambiensis habitat were identified based on a species distribution model and ranked according to their predicted genetic distance to the main tsetse population (Bouyer et al. 2015).

Dispersal of female mosquitoes to seek a host is epidemiologically important because it influences the capacity of the females to acquire and disseminate pathogens. Dispersal to find suitable oviposition sites is also important because it increases the spreading of potentially infected progeny (Petrić et al. 2014). The dispersal of mosquitoes is influenced by the density and distribution of blood sources, availability of oviposition sites, weather, terrain features, vegetation, housing characteristics in urban and rural settings, etc. There appears to be a correlation between mosquito dispersal into new areas and proximity to major transportation routes, commercial movement of tyres, ornamental-plant trade, and individual, public, and commercial transportation out of infested areas (Petrić et al. 2014). 


\subsubsection{Spatial Distribution within Habitat}

Released sterile insects must also disperse into the ecological niches occupied by wild insects, and detailed data on temporal changes in spatial distribution of sterile and wild insects are needed (Lance and McInnis, this volume). This is very challenging; most insects are not uniformly or randomly distributed, but have patchy distributions in both space and time. Spatial heterogeneity is related mostly to host availability and vegetation, making it difficult but not impossible to determine the optimal release rate (number of flies released per $\mathrm{km}^{2}$ ) (Krafsur et al. 1979). An adequate trapping network, covering all types of vegetation, is needed to provide frequent (weekly) detailed information on the density and spatial distribution of wild and released insects. Geographic information systems (GIS) and remote sensing (RS) tools can greatly facilitate the selection of these trapping sites, ensuring adequate coverage but also avoiding the deployment of too many sampling devices (Bouyer et al., this volume). Data on temporal and spatial changes in occupation of the habitat, by both sterile and wild insects, can be used to regularly adapt the scheme for distributing sterile insects.

In the tsetse project in Senegal, selection of trap sites was initially guided using remote sensing techniques and vegetation classifications obtained from Landsat 7 Enhanced Thematic Mapper Plus (ETM+) images that enabled the identification of suitable habitats to harbour G. p. gambiensis with high sensitivity, but low specificity (Bouyer et al., this volume). These areas were denominated "wet areas" and the strategic deployment of Vavoua traps (Laveissière and Grébaut 1990) in these habitats allowed the delimitation of the tsetse-infested area. In the area of zero catches adjacent to the infested area, a mathematical model was used to assess the risk that flies were present despite a sequence of zero catches (Bouyer et al. 2010; Barclay et al., this volume). The analysis showed a risk of $>0.05$ in $19 \%$ of the area which was considered likewise as infested and included in the control operations.

Species distribution models have been used more and more to optimize insect pest control activities in general and to obtain more accurate information on the spatial distribution of the insect pest in particular (Barclay, this volume). Whereas previous distribution models were critical for a better understanding of the distribution of the pest insects, they suffered from inadequate spatial resolution. High-resolution satellite images and recent advances in species distribution modelling methods can be used to improve the accuracy of prediction. For example, in the tsetse eradication campaign in Senegal, the use of a Maxent Model enabled the relocation of 22 of the 97 monitoring traps to more suitable sites according to habitat suitability (Dicko et al. 2014).

On a finer spatial scale, the dispersion of insects such as tsetse flies, e.g. G. palpalis palpalis, is influenced by sex, age (young virgin females occupy different parts of the habitat than older flies), and the state of gravidity in females (Gouteux 1987). These microspatial differences in an apparently similar habitat should be monitored carefully in important target areas, such as "hot spots" (areas with unusually high insect densities).

An example is the spatial occupation of wild and sterile G. austeni in an apparently uniform primary forest ecosystem (Fig. 3). A total of 422 wild female, 679 wild male and 3318 sterile male fly catches from 12 trapping sites over a period of 10 months was used to study the spatial occupation of the flies in a primary forest. The aerial release of the sterile male flies assured their random distribution over the very homogeneous habitat. Despite these uniform aerial release rates, the sterile males redistributed 
themselves and occupied microhabitat niches similar to those occupied by wild insects. This ability of sterile males to aggregate (and therefore locate to) those areas preferred by wild males is of primary importance to ensure adequate sterile-to-wild male overflooding ratios everywhere (Vreysen et al. 2011).
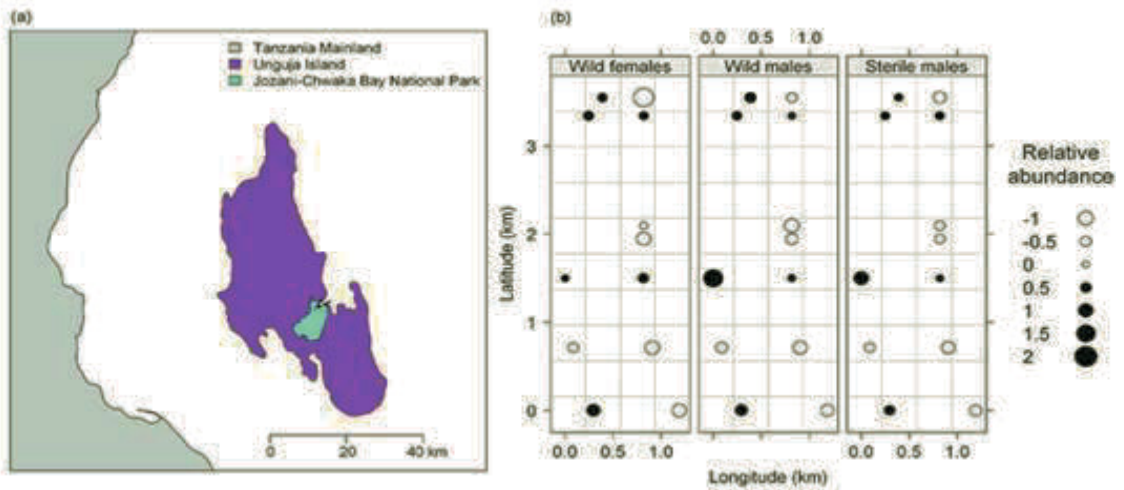

Figure 3. (a) Unguja Island and the Jozani forest (now called the Jozani-Chwaka Bay National Park), (b) The spatial and standardized abundance of wild and sterile Glossina austeni as sampled with 12 sticky panel traps in the Jozani forest. (Figure from Vreysen et al. 2011.)

\section{MONITORING PROGRAMME PROGRESS}

\subsection{Monitoring and Insect Biology}

\subsubsection{Monitoring and Insect Behaviour}

The feasibility of developing and deploying efficient insect monitoring tools will be determined and influenced by the behaviour and the biology of the insect. Species with adults that respond to a trapping device may be sampled directly in sufficient numbers to accurately assess fluctuations in population density and structure. The biological mechanisms involved in attracting insects from a distance, and luring them into a trapping device, are usually related to their host-, food-, or mate-seeking behaviour, which is often regulated by volatile components (semiochemicals) emitted by the host/food/mate, and at close range influenced by visual characteristics (Colvin and Gibson 1993; Tan 1993; Green 1994; Hall and Wall 1995; Lühken et al. 2014). Sometimes direct trapping of insects is difficult (e.g. in inaccessible areas), inefficient (e.g. a good attractant and trap are not available), or uneconomic, and therefore alternative indirect methods of monitoring have been developed, usually involving assessments of damage inflicted by the pest on its hosts (Iwahashi 1977; FAO 1992; Bloem and Bloem 2000; Dyck et al. 2000).

Surveillance programmes for mosquitoes, such as the Asian tiger mosquito Aedes albopictus (Skuse), rely on the use of ovitraps, rather than adult trapping systems. 
Ovitraps are simple devices that consist of plastic cups that have a shiny black surface, are filled 2/3 with water, and contain a Masonite strip on the inner wall that is suitable for oviposition (Carrieri et al. 2009). The maximum time interval allowed for checking the ovitraps is 1 week; longer periods would turn the traps into mosquito reproductive breeding sites (Ritchie 1984). The egg-density data obtained can provide a good estimate of the biting-female density (Carrieri et al. 2011). Monitoring with ovitraps has the advantage of being low cost, but the catch data might be influenced by factors such as siting, micro-environment, presence or absence of other breeding sites, and local adulticide treatments (Carrieri et al. 2017).

\subsubsection{Direct Sampling of Adult Insects}

In AW-IPM programmes, it is important to be able to monitor both high and low population densities. The densities of pests such as screwworms tend to be low but highly aggregated (Krafsur et al. 1979; Spradbery 1994), and the most efficient and appropriate sampling device should be used (Katsoyannos 1994) for the relevant geographical area (Baylis and Nambiro 1993). However, most trapping systems are biased, and samples are rarely representative of the insect population (Vale and Phelps 1978; Vreysen and Saleh 2001). Therefore, it is always a sound practice to estimate population densities using more than one method (Bloem et al. 2005; Petrić et al. 2014; Lees et al., this volume). To interpret trapping data correctly, it is imperative to understand these "trap biases", and the factors that affect the size and structure of trap samples over time and space. Some of the most significant factors that affect insect population samples are: (1) activity of the insects, which depends on the insect's physiological state and on climate (Rogers 1978; Turner 1987; Williams et al. 1990b), (2) efficiency of the trap, which is influenced by the elements of attractant, trap construction, habitat, and climate (Hargrove and Vale 1980; Dransfield et al. 1982; van de Straat et al. 2019; FAO/IAEA 2020a), and (3) intrinsic trap biases (Williams et al. 1990a).

In addition, when selecting a trapping device for a monitoring programme, the following aspects have to be taken into account: performance of the sampling device in relation to economics (number of traps needed is inversely correlated with trap efficiency), servicing, time required to deploy a trap, unit cost and its components, durability, "user friendliness" (i.e. time required to remove trapped insects), efficiency of the bait (very good baits may overestimate the local population density), and species specificity (Flores et al. 2017; FAO/IAEA 2018). Trapping large numbers of non-target organisms is inefficient; e.g. biting flies (Stomoxyinae) caught in tsetse fly traps (more than 1000 individuals per trap per day) (Saleh et al. 1999), species of Chrysomya, morphologically similar to New World screwworms, caught in traps at a ratio of 2600:1 (Spradbery 1994), and a wide range of tephritids and non-tephritids in fruit fly traps baited with food lures (Katsoyannos 1994; Miranda et al. 2001).

Smart traps are now available on the market and are becoming more common for monitoring purposes in action programmes. These sampling devices, which automatically record the target insects sampled and provide feedback using appropriate software systems, have several advantages, e.g. traps need to be checked only when relevant catches have been recorded, preventing unnecessary visits to empty traps and making the entire monitoring process much more cost-effective. In 
addition, new systems are being developed that allow the automatic identification of the insects, reducing or even eliminating the need for trap visits (Vreysen et al. 2016). One of these trapping systems consists of a multi-funnel trap equipped with a camera connected to an internal modem for General Packet Radio Service. Images taken are stored on a memory card and are adequate for identifying larger insects such as longhorn beetles (Chinellato et al. 2013).

The potential use of these systems in sterile insect release programmes would also lead to more cost-effective and efficient field surveillance, as real-time feedback on released insects could lead to more efficient decision-making (Simmons et al. 2010). For example, in Australia, a system called RapidAIM (2018) was developed that combined the knowledge of fruit fly behaviour with proprietary hardware and software used in a grid of instrumented, low-powered smart traps. The traps detect the presence of a fruit fly, send the data to the cloud for analytics, and generate an alert. This system visualizes the location and occurrence of fruit fly presence and/or outbreaks which can result in a rapid and efficient response.

\subsubsection{Indirect Sampling}

Monitoring a population through direct sampling of adult insects can, in many instances, be supplemented by indirect sampling procedures, both to obtain additional information on the progress of the programme and to verify the data obtained by direct sampling procedures. In addition to direct sampling, indirect sampling is used routinely in programmes against veterinary pests (screwworm and tsetse), crop pests (Lepidoptera and fruit flies), and human disease vectors (e.g. mosquitoes).

Monitoring Host Organisms. In many holometabolous insects, immature stages represent a large percentage of the population (up to $97 \%$ for the Mediterranean fruit fly (Carey 1982; Liedo and Carey 1996)), and in view of this demography these stages should also be sampled (FAO/IAEA 2019).

Since it is easy to detect maggots in animal wounds, indirect sampling through the surveillance of myiasis cases in livestock, game animals, and humans has become the standard method of monitoring progress in New World screwworm eradication programmes. Depending on resources, surveillance can be done either passively (livestock owners check their animals and report positive myiasis cases (Robinson et al. 2000)) or actively (programme staff physically inspect at regular intervals all host animals in the target zone (FAO 1992; Vreysen et al. 2007)). Even though passive surveillance is obviously less expensive, the absence of standardization and a "reference-sampling unit" make temporal comparison of such field data very difficult or even impossible. Also, passive surveillance is influenced by: (1) the accessibility that farmers have to their livestock, (2) the willingness of farmers to inspect their animals on a regular basis (and remove screwworm larvae and send them to the responsible authority in the country), (3) the vastness of the grazing area, and (4) the efficiency of veterinary services. Therefore, a decrease in "reported cases" does not necessarily reflect a lower population density of screwworms (i.e. progress in the programme), but is probably correlated more with the reporting efficiency and level of farmer cooperation (Vreysen et al. 2007). The highly successful New World 
screwworm eradication programme in Libya (1990-1992) provides a good example of an efficiently executed active surveillance programme; 94 field teams inspected 16.2 and 30.5 million animals in 1990 and 1991, respectively, in an area of $40000 \mathrm{~km}^{2}$ (FAO 1992). Accurate reporting of the number of animals inspected, wounds detected, and wounds infested, provided excellent feedback to programme managers to evaluate the progress and guide eradication activities (Lindquist et al. 1992).

Monitoring Disease Transmission. In the case of vectors of diseases such as tsetse flies (Glossinidae) that transmit Trypanosoma spp., and mosquitoes that transmit malaria, dengue, chikungunya, Zika, etc., insect-trap data can be supplemented with data on the transmission, prevalence, and incidence of the disease in livestock and humans (Barclay et al., this volume). These data become especially valuable if and when the density of the insect population drops below the detectable limit of the trapping device used. In the case of tsetse, the careful screening of sentinel animals, i.e. not infected with trypanosomes, introduced into the target area can significantly increase confidence that the tsetse fly has been eradicated (Dyck et al. 2000). However, interpreting these veterinary surveillance data is complex, and preferably should always be correlated with entomological monitoring data because:

- The density of a tsetse population and the incidence of the disease are not necessarily positively correlated, e.g. an insecticide spraying campaign in Kenya reduced the tsetse population by $98 \%$, whereas 6 months after completion of the campaign the disease prevalence was reduced only from 5 to $2 \%$ (Otieno et al. 1990).

- The time required for a fly to develop a mature trypanosome infection is between 5 and 25 days, depending on the species and the temperature (Molyneux et al. 1982). Consequently, the potential for a tsetse population to transmit the disease is increased proportionally to its average age (Harley 1965), and the removal of the younger section of the fly population as the result of control actions does not significantly reduce its transmission capability.

- A parasitological survey will not show transmission if a tsetse population is thriving on livestock free of trypanosomes.

A series of indices has been used traditionally to monitor indirectly densities of Aedes spp. and the efficiency of control programmes. These include the:

- house index (HI), i.e. percentage of houses with a least one active breeding site,

- container index (CI), i.e. percentage of containers with larvae,

- Breteau index (BI), i.e. number of active breeding sites per 100 premises, and

- ovitrap index (OI), i.e. average proportion of ovitraps with mosquitoes.

Although widely used, these indices have some disadvantages when used in epidemiological studies, e.g. the CI considers only the percentage of positive containers, and not absolute numbers, and the $\mathrm{HI}$ is limited as it does not take into account the number of positive containers. The BI is the only index that combines positive containers with the density per premise (Petrić et al. 2014).

Other indices that have proven to be very useful are the number of pupae per premise (PPI), and the number of pupae per hectare (PPH), because they exploit the 
strong correlation between the number of adults in a defined area and the number of pupae (in view of the low pupal mortality) (Carrieri et al. 2011).

Monitoring Crop Damage. The damage that insects inflict to crops can be assessed, providing indirect information on the density and distribution of the pest insect population. Crop damage can be measured at regular intervals, e.g. 80-100 cotton bolls per field were collected each week in the pink bollworm programme in California, USA (Staten et al. 1993). Also crop damage can be assessed at harvest, e.g. in the codling moth programme in Canada, a random examination of fruit is made in about one-third of the treated orchards $(n=600)$ at harvest (Bloem and Bloem 2000). Caution is required in interpreting the data, because damage to a specific crop is not always caused by the target insect, e.g. all insect damage in fruit orchards in Washington State, USA, was attributed to the codling moth, but careful study revealed that fruit injury from codling moth larvae was only $0.3 \%$ while that from leaf rollers averaged $1.1 \%$ (Calkins et al. 2000). In some instances, the results of direct monitoring (insect trapping) do not correlate with data from indirect sampling (crop damage), e.g. there was no spatial correlation between damage, i.e. defoliation, from gypsy moths Lymantria dispar (L.) and the counts of adult male moths in traps (Liebhold et al. 1995).

\subsection{Monitoring Impact of Sterile Insect Releases on a Wild Population}

Three important indicators provide essential information on the impact of released insects on the target population: (1) proportion of the female target population that mated with sterile males (level of induced sterility), (2) changes in the age structure of the target population caused by variations in the recruitment rate of young insects, and (3) decline in the density of the target population. The characteristics of the reproductive biology of the species, and the trap-orientation behaviour of females, will determine which of these parameters can be used. For example, all three parameters can be monitored in tsetse fly programmes integrating the SIT, but in Lepidoptera, pheromone traps attract only male moths, and thus the information obtained is restricted to the apparent densities of wild and sterile males.

Analysing and interpreting temporal and spatial monitoring data can be accurate only if standardized sampling procedures are used. Especially in the case of direct sampling, uniformity of procedures is required for the entire duration of the monitoring programme, particularly with respect to: (1) trapping device (type, colour, material used for trap construction, shape, etc.), (2) sampling sites (number and location), (3) trap mounting and deployment, (4) lures or odour attractants (chemical composition, $\mathrm{pH}$, volatile release rates, etc.), and (5) sampling interval. In addition, baseline data (collected before control actions are initiated) on spatial and temporal fluctuations in the density and structure of the target population (Itô et al., this volume), collected over a period of at least 1 year, are essential for making correct interpretations of the field data collected during the suppression and sterile insect release phases (Vreysen and Khamis 1999; Vreysen et al. 1999a; De Longo et al. 2000) (Box 1). An alternative is to collect comparable data from an untreated area 
during the phase when control actions are applied, but it is often difficult to select ecologically comparable areas (Waterhouse et al. 1976).

Box 1. Pre-Control Entomological Baseline Data Collection: Prerequisite for Correct Interpretation of Trap Catch Data during Control Activities

The application of a control measure against an insect population will change the size of that population (section 3.2.4.) and its age structure (section 3.2.3.). Even when not subjected to a control measure, insect populations (in terms of both size and structure) are not stable in time and space. Consequently pre-control data on the structure of the target population must be collected to interpret correctly sampling data obtained during the control activities.

Physiological age grading is feasible for tsetse flies due to the uniqueness of the female reproductive system (section 3.2.1.). The example below demonstrates the spatial differences in the age structure of the tsetse fly Glossina pallidipes Austen sampled in riparian forest vegetation along the Kulfo River and in the Chamo bush thickets of the Nechisar National Park in Ethiopia. The flies were sampled in both habitats during the same period of the same day. The data show that the female fly population along the Kulfo River was significantly younger $(18.8 \%$ young females, tenerals and nulliparous $)$ than the female fly population in the Chamo thickets $(6.4 \%$ young females $)\left(\chi^{2}=10.80, \mathrm{df}\right.$ $=4, P<0.03$ - females in the older categories 4 and $>4$ were pooled in this analysis). A change in fly population structure due to applied control measures must be analysed in relation to these natural spatial (and also temporal) differences.
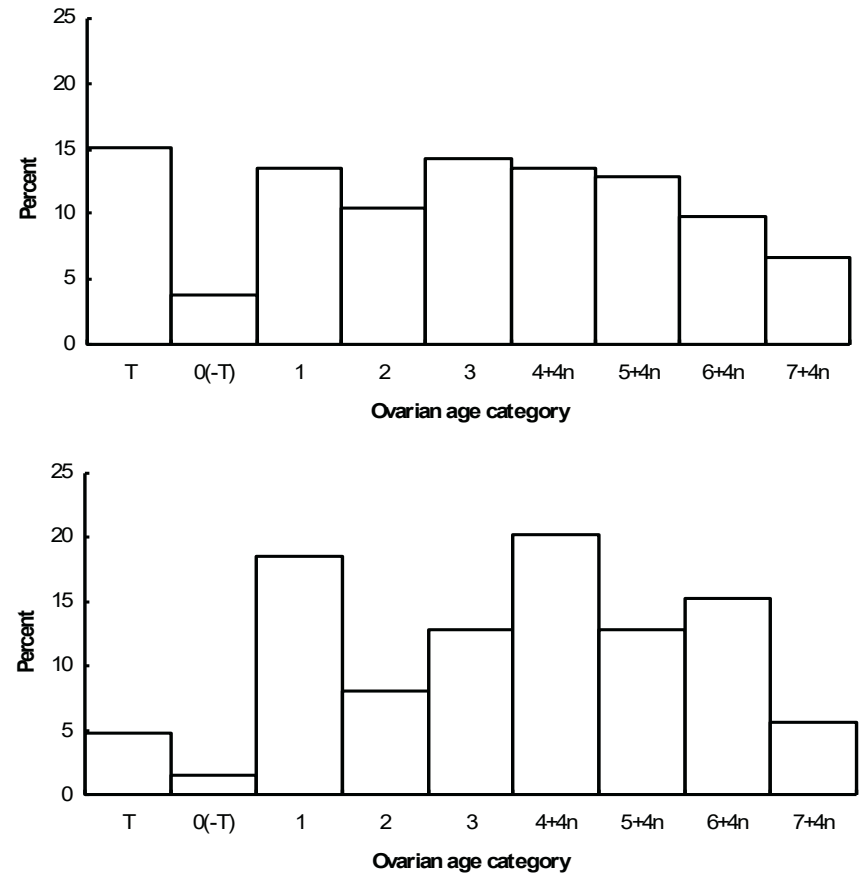

Population structure of $\mathrm{G}$. pallidipes sampled in (upper graph) riparian forest along the Kulfo River $(n=133)$ and (lower graph) bush thickets $(n=124)$ of the Nechisar Park in Ethiopia $(T=$ teneral, $0=$ nulliparous, $1-7=$ number of ovulations; note that categories $i=4-7$ contain flies that have ovulated $i+4 n$ times; more details in Challier 1965). 
Quantifying a reduction in the reproductive potential of a target population constitutes the most powerful and straightforward tool to assess progress in a programme using the SIT (Waterhouse et al. 1976; Vreysen 2001). An accurate knowledge of the level and spatial distribution of sterility induced in wild females will permit a more strategic use of the sterile insects, resulting in increased programme efficacy and reduced programme costs. Assessing the rate of induced sterility in a wild target population is only possible when the female portion of the population can be sampled, and when morphological indicators or "visual markers" are present in the female reproductive system to differentiate between matings with wild or sterile males. Alternatively, female insects can be trapped live and then maintained in controlled conditions for a certain time period to monitor the production of viable offspring (result of a fertile mating) or non-viable eggs (result of a sterile mating). In some insects, egg masses can be collected in the field and the level of sterility determined (section 3.2.2.).

The rate of induced sterility is not only the most essential, but also the most reliable, parameter to assess progress in programmes that release sterile insects. Although a reduction in the number of insects caught in traps can be an important indicator, the number trapped is strongly affected by numerous (often unknown) factors (section 3.1.2.), making the interpretation of trap catches complex (section 3.2.4.). A progressive increase in the sterility of the target population, combined with declining numbers of insects trapped, will provide unequivocal evidence that the eventual collapse of a target insect population is due solely to the loss of fertility, without interference of other factors (Vreysen et al. 2000).

\subsubsection{Monitoring Reproductive Capacity of a Wild Population - Tsetse Flies}

Tsetse flies have a unique reproductive system, making them very suited to the assessment of sterility levels in a population subjected to sterile insect releases (Van der Vloedt et al. 1978; Vreysen et al. 1996). Tsetse flies reproduce by adenotrophic viviparity (Hagan 1951). The four polytrophic ovarioles in the reproductive system of females develop sequentially (Saunders 1960) (Fig. 4A), with only one oocyte maturing per pregnancy cycle lasting 9 or 10 days (Tobe and Langley 1978). Consequently, the maturation stage of the developing oocyte (the next to ovulate) in fertile females is always in sequence with a particular development stage in utero, i.e. embryogenesis or one of the three larval stages (Challier 1965). Mating a virgin female tsetse with a sterile male will result in fertilization of the egg in utero by the sperm, carrying dominant lethal mutations that will result in the death of the embryo (embryonic arrest) (LaChance et al. 1967), which is later aborted (Van der Vloedt et al. 1978). Consequently, aberrations between the size of the maturing follicle and the development stage in utero (dead embryo or uterus empty due to expulsion of the embryo) will become apparent (Vreysen et al. 1996) (Fig. 4B).

Dissection of a reasonably sized sample of wild female flies from a population subjected to sterile male releases will show the proportion of females in the sample that have aberrations in their reproductive system - a direct indication of the rate of induced sterility in the target population (Vreysen et al. 2000). The only weakness in the methodology is the 1- or 2-day time lag between fertilization of the egg with the irradiated sperm and embryonic arrest becoming visible with a microscope (Van der 
Vloedt and Barnor 1984). This could result in underestimating the level of induced sterility.

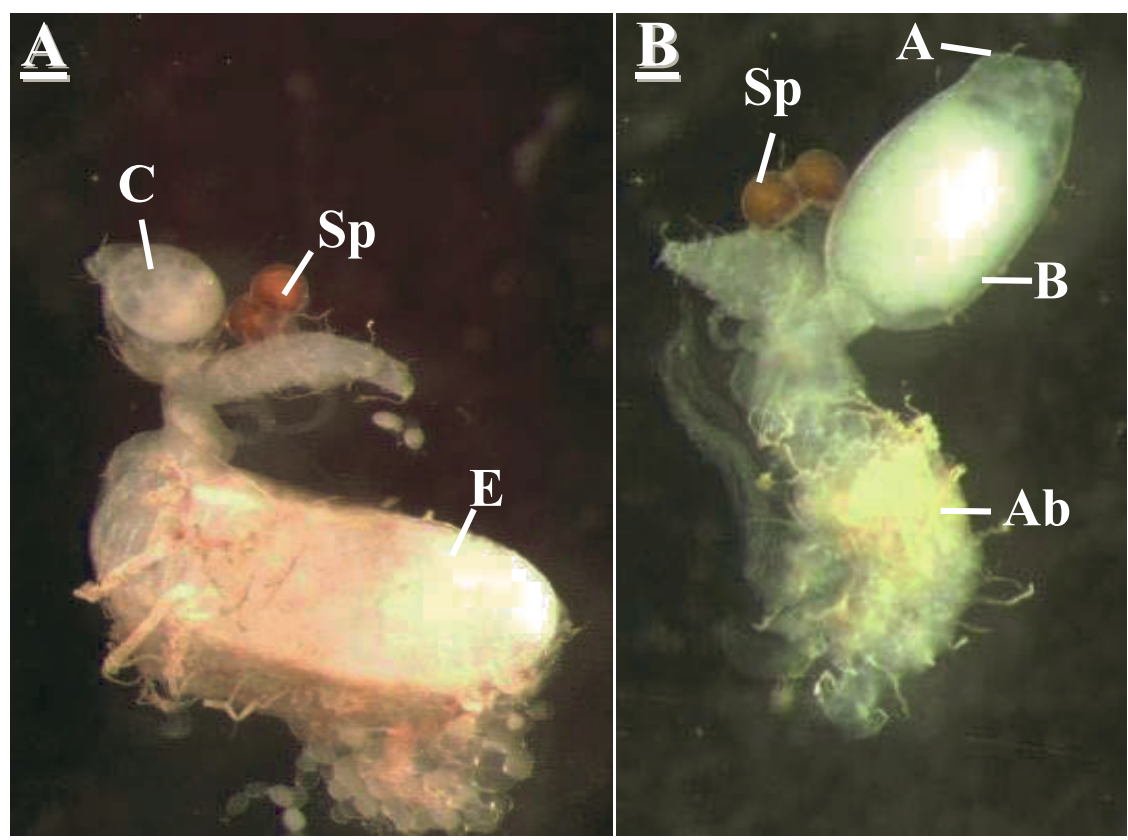

Figure 4. A. Reproductive system of female tsetse fly mated with fertile male, showing one ovulation $(C=$ follicle next in ovulation sequence (FNOS)) and viable egg $(E)$ in utero. $B$. Reproductive system of female mated with sterile male, evidenced by imbalance between size of FNOS (B) and uterus content ( $A b=$ abortion, $S p=$ spermathecae).

Pre-control baseline data from female tsetse flies on Unguja Island, Zanzibar, showed that 50 and $46.1 \%$ of females had a viable egg or larva in utero, respectively, and only $3.5 \%$ of females had an empty uterus showing the loss of an egg or larva (natural abortion rate) (Vreysen and Khamis 1999) (Fig. 5). During the initial 8 months of the SIT activities (mid 1994-early 1995), an insufficient number of sterile males was released, and consequently the ratio of sterile to wild males remained below 10:1. In spite of this low ratio, during this period $19.9 \%$ of sampled females had mated with sterile males (Vreysen et al. 2000). In 1995, the number of sterile males released constantly increased, and more than 50 sterile males for each wild male were trapped after week 34. Simultaneously, the frequency distribution of the uterus content of the sampled females became progressively more distorted compared with the pre-control distribution, i.e. $\chi^{2}=70.3$ in early 1995 and $\chi^{2}=196.6$ in late $1995(\mathrm{df}=4 ; P<$ 0.0001 ), due to a gradual increase in the proportion of females that had aborted dead embryos or displayed eggs in utero in embryonic arrest (Vreysen et al. 2000; Vreysen 2001). 

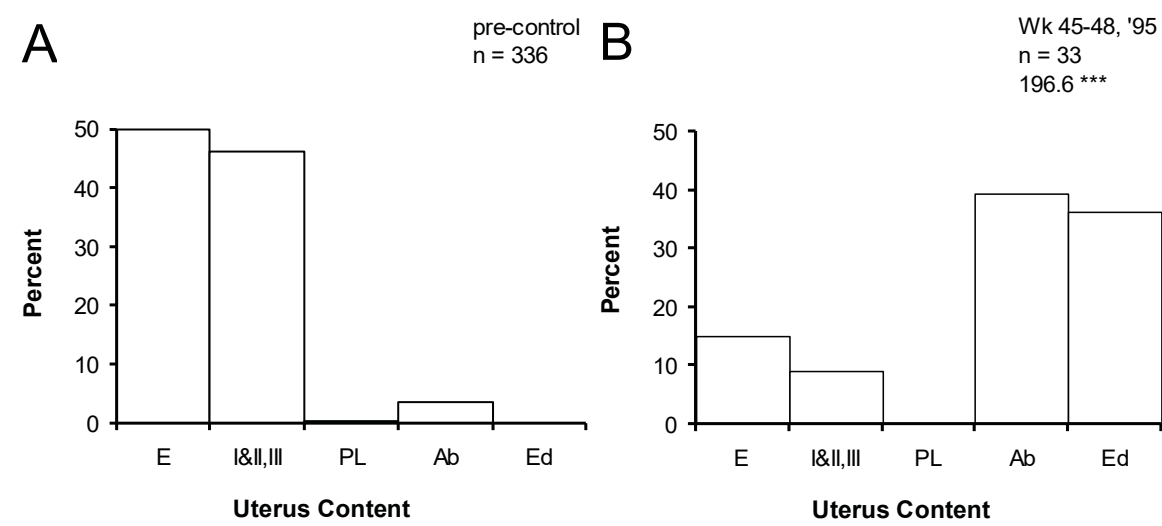

Wk 45-48, '95
$\mathrm{n}=33$

$196.6 * * *$

Figure 5. Frequency distribution of uterus content of Glossina austeni females sampled during (A) pre-control phase and (B) late in sterile male release phase $(E=e g g, I, I I, I I I=$ first-, second-, and third-instar larva, $P L=$ post larviposition, $A b=$ abortion, $E d=$ degenerating egg). Number is chi-square value of comparison of frequency distribution of uterus content with that of pre-control sample $(* * * P<0.001)$. (Figure adapted from Vreysen 2001, reproduced with permission.)

A similar trend can be observed in Fig. 6, which shows data on the reproductive status of young parous females ( 1 or 2 ovulations) that had mated with a sterilized male 2 or 3 weeks previously. It is very evident that the sterility level in the young female population gradually increased as the sterile to wild male ratio increased, i.e. from $26 \%$ in the last quarter of 1994 to 32,48 , and $72 \%$ in the $2^{\text {nd }}, 3^{\text {rd }}$, and $4^{\text {th }}$ quarters of 1995, respectively. Concurrently, as sterility in the young female fly population increased, the proportion of young female flies with a viable larva in utero (females mated with a wild fertile male) decreased.

\subsubsection{Monitoring Reproductive Capacity of a Wild Population - Screwworms, Lepidoptera, and Fruit Flies}

Assessing the rate of induced sterility in screwworms, Lepidoptera, and fruit flies is more challenging. No differentiation between sterile and fertile matings can be made by direct examination of the reproductive system of sampled wild females. Any quantification of sterility levels in wild females requires the collection and maintenance of eggs, and an assessment of the ratio of hatched (fertile) to non-viable (sterile) eggs (Thomas and Mangan 1989). For screwworm, fruit fly and lepidopteran species, special egg collecting methods have been developed (Davis et al. 1968; Snow et al. 1976; Parker and Welch 1991; Katsoyannos et al. 1999), but most are labourintensive and expensive to implement in large operational programmes. The usefulness and applicability of these methods vary for each insect group (see below). 

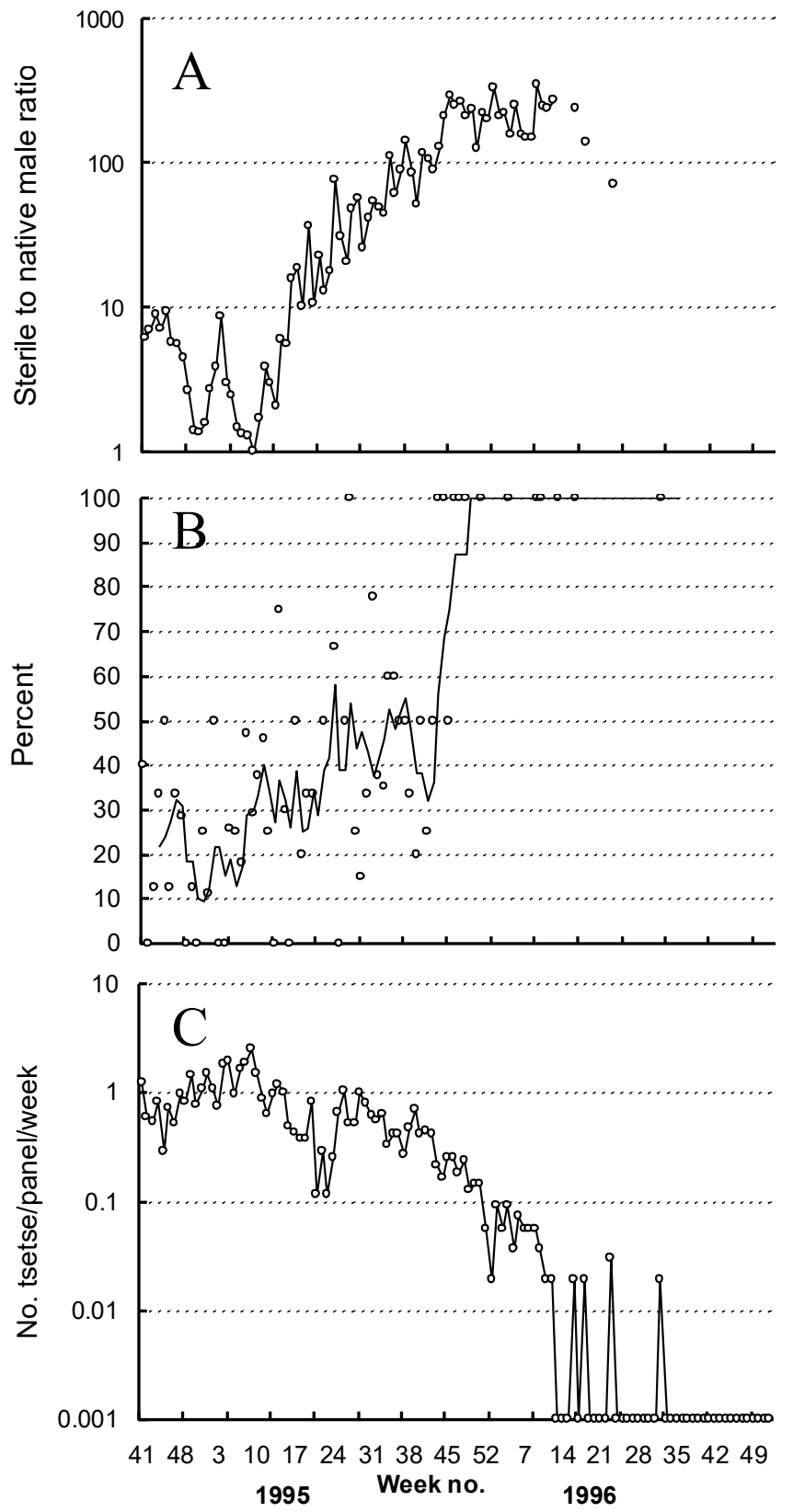

Figure 6. A: Sterile to wild male ratio. B: Rate of induced sterility as proportion of young parous females (1 or 2 ovulations). C: Apparent density (+ 0.001) of wild males and females. Glossina austeni, Unguja Island, Zanzibar. (Figure adapted from Vreysen et al. 2000, reproduced with permission.) 
Induced Sterility and Egg Collection. In female screwworm flies, with 100-150 ovarioles per ovary, egg development is synchronous, and an average of 200 eggs are deposited (Thomas 1993), regardless if eggs are fertilized by fertile or sterile sperm (LaChance and Bruns 1963). Egg masses can be collected in several ways: (1) from artificially inflicted wounds on sentinel animals, maintained in fixed capture stations (Davis et al. 1968; Parker and Welch 1991; FAO 1992), (2) from wounds found by field inspectors during routine surveillance activities (Robinson et al. 2000), and (3) from gravid females that were attracted to, and caught in, liver-bait stations and "egged" in glass tubes (Parker and Welch 1991). Maintaining sentinel pens is cumbersome, difficult to implement in some countries in view of animal right issues, and rather problematic in tropical remote environments because of the paucity of suitable animals, water, shade, and animal food (Krafsur and Highthower 1979; Parker and Welch 1991). (It would be convenient if some kind of artificial wound were available to collect eggs from wild screwworm females; such a methodology needs to be developed.)

Training and expertise are needed to detect and identify screwworm fly eggs. Also they are short-lived, and inappropriate handling often causes increased mortality, resulting in overestimates of the rate of induced sterility. In addition, one egg mass is not necessarily the output of one female, as was originally assumed (Krafsur et al. 1979; Brenner 1984), but possibly the product of more than one female (eggs laid beside eggs already deposited by another fly) (Thomas and Mangan 1989), making it difficult to interpret sterility data. Nevertheless, the most manageable option at present is the systematic collection of egg masses from animal wounds during routine surveillance along a predetermined grid network, and adequate geo-referencing of the sampling sites for incorporation into GIS (Bouyer et al., this volume), providing accurate information on the spatial and temporal distribution of induced sterility in the wild population.

The development of female lures has recently brought about significant progress in monitoring the Mediterranean fruit fly (IAEA 1999) (Box 2). However, as with screwworms and Lepidoptera, dissection of female fruit flies does not reveal any difference between fertile and sterile matings. Therefore, live-trapped female Mediterranean fruit flies can be transferred to a cage containing a natural or artificial oviposition substrate, egg masses collected, and egg hatchability assessed (IAEA 1999; Katsoyannos et al. 1999). Except for experimental trials, methods such as maintaining fruit fly eggs dissected from collected fruits to assess hatchability (Wong et al. 1986; McInnis et al. 1994), or measuring the size of the head of spermatozoids collected from spermathecae of female flies to differentiate between sterile and fertile sperm (McInnis 1993), have never been applied because they are cumbersome. Nevertheless, eggs from wild Mediterranean fruit flies were collected from coffee berries in Guatemala and induced sterility calculated (Rendón et al. 2004). Also, an artificial oviposition device, to collect eggs from female melon flies netted in the field, was developed and used successfully to assess egg hatchability during the programme on Kume Island, Japan (Iwahashi et al. 1976; Iwahashi 1977).

A significant development is the availability of a reaction-restriction fragment length polymorphism-based method (PCR-RFLP) to identify the origin of sperm in captured wild female Mediterranean fruit flies. The method identifies Y chromosomes 
in DNA extracts from the spermathecae, enabling the identification of the genetic origin of the sperm, i.e. wild, sterile or both, as an indicator of the degree of induced sterility in the target population (Juan-Blasco et al. 2013; Krafsur and Ouma, this volume). Another method is to use rhodamine dye to mark the sperm of male insects that can then be detected in the spermathecae or spermatophores of their female mates (Johnson et al. 2017). The potential of using stable isotopes for labelling sperm was studied under laboratory conditions for the mosquito Anopheles arabiensis Patton. Spermathecae filled with labelled sperm could be successfully distinguished from spermathecae with unlabelled sperm (Helinski et al. 2007). All these methods open new avenues to assess mating frequencies (and hence programme progress) in programmes that have an SIT component.

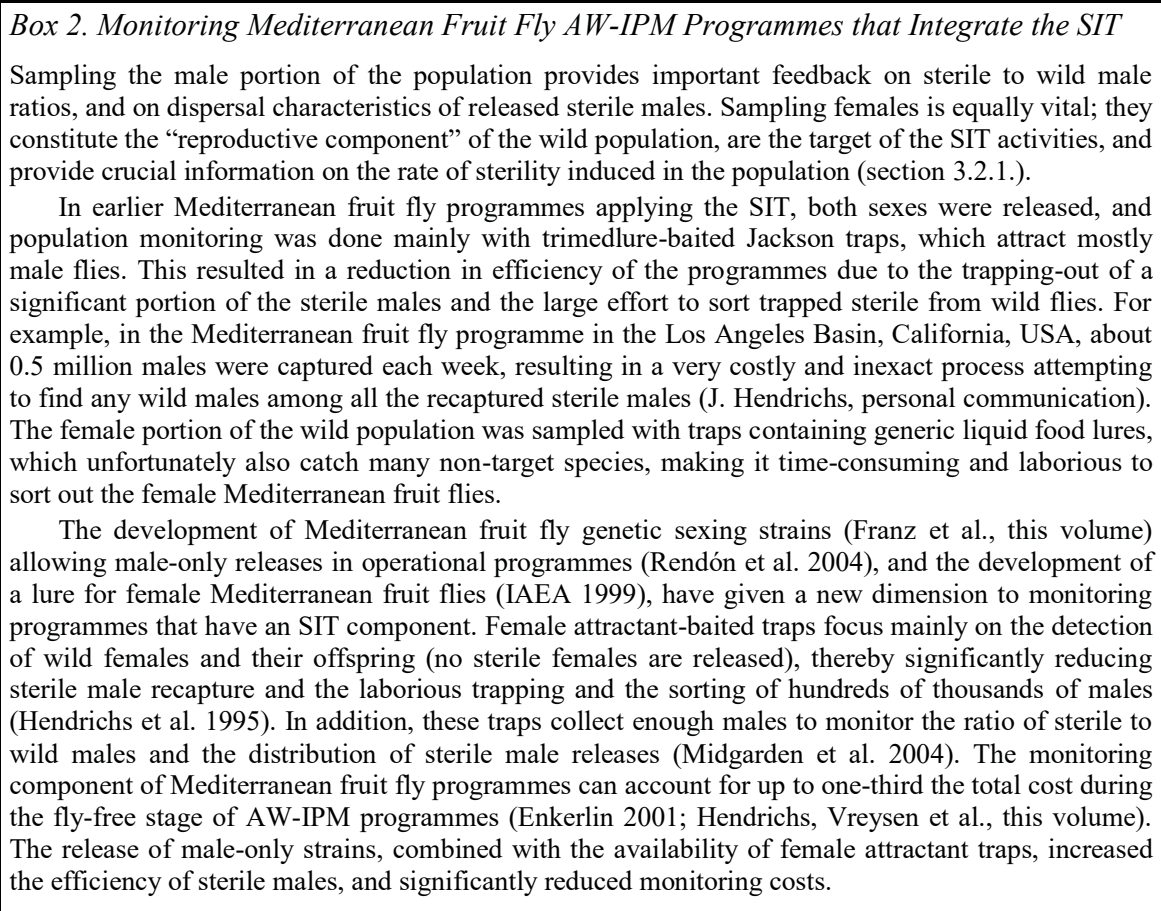

Problems Associated with Trapping Female Lepidoptera. Monitoring progress in lepidopteran programmes relies mainly on crop damage assessments and on traps using potent female sex pheromones as lures (Riedl et al. 1986; Bloem and Bloem 2000; Walters et al. 2000). The pheromone traps attract only male moths, and sterile moths can be distinguished from wild moths if appropriate marking techniques are used (Dyck et al. 1993; Parker, Mamai et al., this volume) (section 2.1.). Therefore, trap samples will indicate the apparent densities and ratio of wild and sterile moths, but the absence of females in the samples precludes any data on sterility levels induced in the wild population. In addition, the deployment of pheromone traps has to 
be well balanced to prevent the trapping of too many sterile male moths, which reduces the efficiency of the SIT component of the programme.

Several methods have been developed to assess sterility in moth populations using tethered (Alford and Silk 1983) or clipped-wing sentinel/decoy virgin females placed on mating tables (Snow et al. 1976; Shaver and Brown 1993), in virgin-female traps (Snow et al. 1969), or in mating houses (Mastro and Schwalbe 1980). These female moths will attract male moths, and it is assumed that the virgin females mate with sterile and wild male moths at the same periodicity and frequency as occurs in nature. Mated females are then transferred to controlled conditions, where deposited eggs are screened for sterility. The "tethering" or "clipped-wing" method is, however, hampered by the small size of many lepidopteran species, and by numerous escapes, although Teflon ${ }^{\circledR}$-walled mating tables may prevent escapes (McBrien and Judd 1996). Also, if the design of mating houses interferes with the entrance response of males, such cages would not be suitable.

A pear-derived volatile (ethyl (2E,4Z)-2,4-decadienoate), which acts as a kairomone (chemical emitted by one species and attracting another) for codling moth males and virgin and mated females, has been available for the last two decades (Light et al. 2001). It enables the trapping of live female codling moths; this greatly facilitates the collection of egg masses for screening sterility but also permits the sampling of females in an economic and systematic way over large geographical areas in operational programmes that use the SIT. This discovery has promoted the search for kairomones that are efficient for other lepidopteran pest species, such as the diamond back moth.

In that respect, a recent study on the morphology and distribution of antennal sensilla of the diamondback moth showed that each sensillum contained three cocompartmentalized olfactory receptor neurons (ORNs). Each ORN class showed a narrow response spectrum, with some ORNs specialized for green-leaf volatiles and $( \pm$ )-linalool that are present in brassicaceous hosts, while several other ORNs responded to two non-host volatile sesquiterpenes, (E)- $\beta$-farnesene and germacrene $D$, as well as (E)- $\beta$-caryophyllene, a host-related sesquiterpene volatile (Wee et al. 2016). In addition, other studies showed that female moths were significantly more attracted to conspecific larvae-infested cabbage plants, had significantly shorter flights than in fields with intact uninfested cabbage hosts, and oviposited significantly more eggs on larvae-infested cabbage than on intact uninfested cabbage (Wee 2016). These data indicate the potential of developing a brassica host-derived kairomone attractant for female diamondback moths that could be used for sampling purposes.

Distinguishing $F_{1}$ Males from Wild Males in Inherited Sterility Programmes of Lepidoptera. Inherited sterility in lepidopteran programmes has a distinct advantage over full sterility in that the released semi-sterile males have a better mating competitiveness than fully sterile males, in addition to the resulting multiplier effect from viable but sterile progeny from every mating. The deleterious effects induced by irradiation are inherited by the $F_{1}$ generation, but it is very difficult to measure progress in population suppression because the $F_{1}$ offspring are not marked and therefore cannot be distinguished from wild males. Using light microscopy, the incidence of chromosomal aberrations in $F_{1}$ male larvae can be used to reveal the 
proportion of moths that mated with released substerile males. Fragmentation, and non-reciprocal, reciprocal, and multiple translocations, are the most common types of aberrations encountered (Marec et al., this volume).

A forensic biosecurity method, based on a cytological assessment of sperm bundles of wild and $F_{1}$ males, has been developed and shows great promise. The technique can successfully distinguish the homogeneous nuclei clusters of eupyrene bundles of the normal fertile males from the heterogeneously stained nuclei clusters of the $F_{1}$ progeny. This technique has been demonstrated in six lepidopteran species: codling moth, cactus moth, diamondback moth, painted apple moth Teia anartoides Walker, corn earworm Helicoverpa zea (Boddie), and fall armyworm Spodoptera frugiperda (J. E. Smith) (Carpenter et al. 2009; Wee et al. 2011). However, the technique only yielded good results when good specimens for cytological diagnosis were obtained. In addition, the percentage of positive staining results was strongly correlated with survival. Moths that had spent $24 \mathrm{~h}$ on a sticky base in a monitoring trap were equivalent to freshly killed specimens, but the efficacy of the technique decreased after that (Wee et al. 2011).

\subsubsection{Monitoring Variations in Age Structure of a Wild Population}

A change imposed on an insect population through variations in mortality, emigration, and invasion, will be reflected in the age structure of that population (Van der Vloedt et al. 1980; Rogers and Randolph 1986; Vreysen et al. 1999a). A method to determine the age of individual insects (or a group of insects) would enable variations in population structure resulting from the control measures to be assessed, and would be another powerful tool to monitor progress in programmes. The effects of season, habitat, and other factors on the age structure of a population must be separated out from those of applied control measures.

There are several methods that have routinely been used in operational programmes to estimate the age of tsetse fly populations (Van der Vloedt et al. 1980; Vreysen et al. 2000) — the development stage of ovarioles in females (Saunders 1960; Challier 1965), and the wing-fray analysis (rate of wear of the wings) (Jackson 1946). Wing-fray measurements are a convenient way to give a reasonable, albeit crude, indication of the mean age of a population, but since fraying is influenced by the activity pattern of flies, the rate of wing fraying varies between species and the sexes (Ryan et al. 1980). Determining the physiological age structure in tsetse, using ovarian development (section 3.2.1.), is labour-intensive but very accurate. However, it is not suitable for determining the chronological age of tsetse populations, in view of the influences of temperature and nutritional state on the development rate of each gonadotrophic cycle (Saunders 1972), and inter- and intra-species differences (Wall 1990).

The measurement of fluorescent pigments (pteridines), which accumulate linearly with age in the heads of tsetse flies (Lehane and Mail 1985; Langley et al. 1988) and New World screwworms (Thomas and Chen 1989), and curvilinearly in the Old World screwworm Chrysomya bezziana (Villeneuve) (Wall et al. 1990), may provide a cheap, convenient, and rapid indicator of the mean age of these insect populations. However, the level of pteridine accumulation is highly dependent on temperature and fly size. Also, the precise age of individual insects cannot be determined because the 
levels of residual variation in pteridine fluorescence remain unexplained in all cases studied, and appreciable confidence limits must be placed around pteridine-derived age estimates (Wall et al. 1990). According to field studies, this method was not suitable for accurate age determination in Mexican fruit flies Anastrepha ludens (Loew) (Tomic-Carruthers et al. 2002).

Near-infrared spectroscopy (NIRS) has been used to estimate the chronological age of stable flies Stomoxys calcitrans (L.), house flies Musca domestica L., and face flies Musca autumnalis De Geer. NIRS has several advantages over the pteridine fluorescence technique for age-grading field-collected insects (e.g. speed and portability of instruments). The technique is independent of the sex and size of the insects being studied, and of the temperature to which adult insects were exposed (Mendoza et al. 2002).

Releasing competitive sterile males will gradually increase the proportion of wild females that do not produce viable offspring. Consequently, fewer young insects will be recruited into the population, and the age structure will gradually become skewed towards older age groups, e.g. data from the tsetse programme in Zanzibar (Fig. 7). During the early stages of the release programme, the monthly averages of the proportion of teneral and nulliparous (i.e. young) females in the samples (determined by ovarian ageing) fluctuated between 16 and $19 \%$, whereas the monthly averages of the proportion of old females (with 4 or more ovulations) fluctuated between 18 and $28 \%$. Thereafter, the proportion of young flies decreased progressively, whereas the proportion of old females ( $\geq 4$ ovulations) gradually increased (Vreysen et al. 2000).
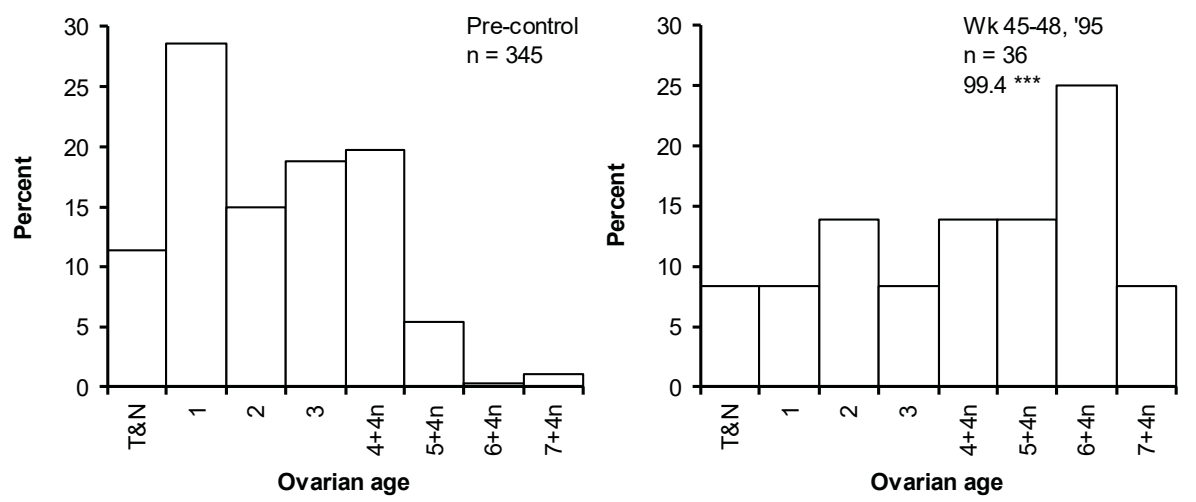

Figure 7. Frequency distribution of ovarian age categories of G. austeni females sampled during (left) pre-control phase and (right) late release phase ( $T=$ teneral, $N=$ nulliparous, $1-7=$ number of ovulations; more details in Challier 1965). Number indicates chi-square value of comparison of frequency distribution of ovarian age with that of pre-control sample $\left(*^{* *} p<0.001\right)$. (Figure adapted from Vreysen 2001, reproduced with permission.) 


\subsubsection{Monitoring Relative Abundance of a Wild Population}

Decline in the apparent density of a wild population, as shown by the number of insects trapped in a sampling device, is a commonly used parameter to assess the progress of AW-IPM programmes for fruit flies (Iwahashi 1977), Lepidoptera (Bloem and Bloem 2000; Walters et al. 2000) and tsetse flies (Vreysen et al. 2000) (Fig. 6). In the case of insects with a very long lifespan, such as tsetse flies (Vreysen et al. 1996), monitoring this parameter has an inherent weakness; no insects are actually killed by the SIT technology, and thus there is an inevitable delay in the decline in the number of wild insects available to be trapped.

When sampling insects to obtain an indicator of programme progress, the main difficulty is related to interpreting catch data. For example, is a temporal decline in the number of insects trapped, even when using a standardized monitoring programme, always an indication of progress in a control programme? Numerous factors influence the size of trap samples (section 3.1.2.), and the importance of these factors for the interpretation of monitoring data is illustrated below.

The density of a natural insect population rarely remains stable, but fluctuates in both space and time. Knowledge of these fluctuations is prerequisite to correctly interpreting monitoring data. In the absence of any control measure, monthly trapping data for the tsetse fly Glossina swynnertoni Austen, over a period of 23 years in Tanzania (Fig. 8), show high seasonal variations in the apparent density of the population, with the average highest apparent density being 18 times that of the lowest average density (Glasgow and Welch 1962).

Differences in population density from one place to another can be great. Locations with unusually high densities are called "hot spots" and require special attention in AWIPM programmes (sections 2.1. and 2.2.3.) (Box 3).

In addition to the need for baseline data on the temporal and spatial fluctuations in the density of a wild insect population, the factors that influence changes in the behavioural responses of insects towards trapping devices, in both space and time, need to be understood to correctly interpret monitoring data (Vreysen and Saleh 2001). An analysis of weekly trap catches of sterile Glossina austeni released on Unguja Island, Zanzibar, over a period of more than 2 years, showed that, in each 12 month period, the size of catches fluctuated by a factor of more than 10 , independent of the actual sterile fly population density (which was estimated from the number of sterile males released) (M. J. B. Vreysen, unpublished data). These data led to some important lessons. Even dramatic increases in trap catches, especially during control operations, could wrongly be attributed to sudden explosions of the pest population, migration from adjacent areas, decrease in mortality, or failure of the applied control method. This study indicates that the probability of trapping insects during a postcontrol monitoring phase would be increased significantly by deploying traps during strategic periods, e.g. when the behavioural response of insects to the trapping device is at a high point (Saleh et al. 1999). 


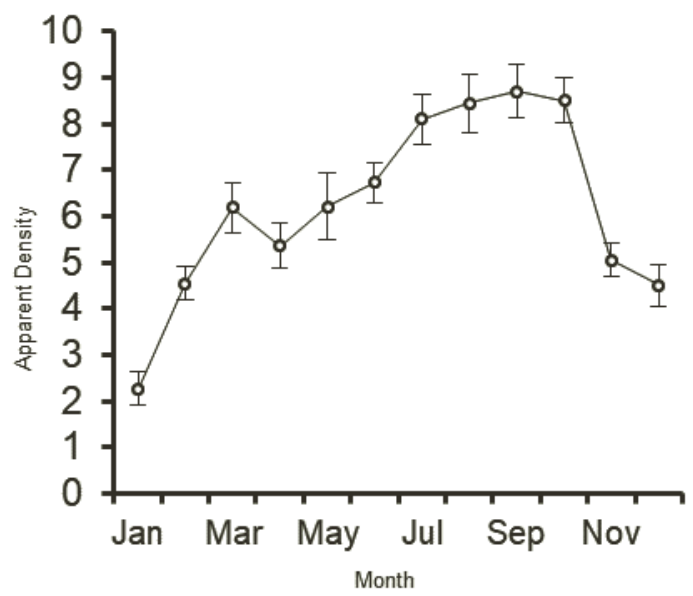

Figure 8. Fluctuations in average monthly apparent density (as percentage of total catches) of Glossina swynnertoni population sampled over period of 23 years in Tanzania. (Figure adapted from Glasgow and Welch 1962, reproduced with permission.)

Box 3. Monitoring "Hot Spots"

Localized infestations or "hot spots" are of particular interest in AW-IPM programmes (Shiga 1991). Strategies that allow quick action to manage these situations are required. To detect hot spots quickly, programme managers must always be alert throughout the duration of the programme. The early detection of relic populations, or reinfestations in localized areas, is a determining factor in reducing programme cost, in increasing programme effectiveness, and in the ultimate successful completion of the programme (Itô and Kakinohana 1995). Although baseline surveys might reveal that the pest infestation is widespread, hot-spot areas are often concealed, and are revealed only after the programme has advanced.

The reasons for hot spots are numerous - localized ideal climatic conditions, abundant hosts, and in some cases also presence of difficult topography that hampers the effectiveness of pre-release suppression activities (Nakamori and Shiga 1993).

When hot spots are discovered or persist, surveillance in the vicinity should immediately be increased. The size of the area under surveillance will depend on the mobility of the insect, and should be increased systematically until no more wild insects are trapped. The traps deployed must be serviced/emptied on a very frequent (daily) basis, or the frequency and intensity of indirect sampling procedures (fruit inspection, disease monitoring, etc.) (section 3.1.3.) increased, to amplify confidence in the data. For some insect species such as the Mediterranean fruit fly, DNA analysis can indicate whether the infestation is new, or originates from a relic population or from insects that accidentally escaped from a rearing facility (McInnis et al. 2017). If the infestation is new, it is essential that live wild insects are collected in the new infestation zone, and their mating compatibility with factory-reared and sterilized insects assessed. In addition, the overall monitoring efficiency needs to be increased by immediately installing a high-density delimitation trapping grid around each incursion (FAO/IAEA 2018), and improving communication and/or feedback mechanisms with crop farmers or livestock keepers to reduce the time between an infestation being discovered and it being reported to programme management or relevant authorities.

After assessing and compiling the necessary information, using GIS (which can greatly facilitate the analysis and management of localized infestations (Bouyer et al., this volume)), corrective measures must be taken immediately, e.g. apply an insecticide, increase the number of sterile insects released, create a buffer zone or quarantine programme, and limit the movement of livestock, crops, etc. 


\section{ESTABLISHING THE ABSENCE OF INSECTS}

After the "last" wild insect has been caught, a difficult decision must be made. When should the release of sterile insects be terminated? Stopping the release too soon could jeopardize the success of the programme, but if releases are continued after eradication has been achieved, useful resources are wasted (Proverbs 1974). The time period of continued releases but zero captures will be influenced by the life cycle of the insect, the efficiency of the sampling system used, and the financial resources available.

To increase the confidence of detecting wild insects during and after the final stages of an eradication programme, the monitoring strategy could be adjusted by: (1) increasing the density and frequency of the direct and indirect monitoring activities (Yamagishi et al. 1993), (2) increasing the proportion of sampling devices biased for the female segment of the population (to obtain more information on fertility or induced sterility) (Vreysen et al. 2000), and (3) releasing sterile females as sentinels (Vreysen and Van der Vloedt 1992). The decision to stop releasing sterile insects is frequently made on an ad hoc basis, and is highly influenced by financial and political circumstances. In the eradication programmes in Central America and in Libya, after the "last" case had been detected, the dispersal of sterile New World screwworms continued for 6-18 months (FAO 1992; Wyss 2000). In fruit flies, it is standard procedure that delimitation trapping continues for at least three fly generations (using degree-day models) after the "last" fly has been detected (FAO 2016).

A problem related to the issue of when to stop dispersing sterile insects is how long to continue post-release monitoring to obtain sufficient confidence that a pest has been eradicated (Barclay and Hargrove 2005; Hargrove 2005; Barclay et al., this volume). A sample can only confirm that individual insects are present in a given area; sampling can never prove a negative (McInnis et al. 2017). However, samples can demonstrate that the number of individuals is within a specified range, with a known degree of confidence (Venette et al. 2002). The probability of detecting rare individuals is directly related to the number of sampling units and the density of the population (McArdle 1990; Lance and Gates 1994). Therefore, verification sampling should be implemented in high-risk areas and previous hot spots after termination of releases so as to maximize the probability of detecting relic insects in the field (McDermotte 2000; FAO/IAEA 2018). If too few samples are taken, an error could be made in concluding that a pest is absent from a habitat (Venette et al. 2002).

As the declaration of the absence of an insect in a target area cannot be guaranteed, it must always be qualified by probability or confidence levels (Barclay et al., this volume). Unfortunately, standardized probability-based entomological criteria to confirm the status of eradication have rarely been applied in insect eradication programmes.

An option is to follow the approaches used by ecologists to assess species extinction (McDermotte 2000). In one approach, after extinction is assumed to have occurred, the number of negative sightings required to confirm extinction at a given probability level is assessed; this requires an accurate knowledge of the sensitivity of the sampling method (Reed 1996). A second approach takes into account data from pre-eradication sampling, assuming a declining population. In this method the probability of extinction is estimated as a function of the frequency of pre-eradication 
sightings, and the proportion of the total time (pre- and post-eradication) during which no sightings have been made (Solow 1993).

\section{DATA MANAGEMENT}

It is essential that information from the monitoring activities is reliable, comprehensive, and clear, and is delivered in a synthesized and timely manner to decision-makers (Reyes et al. 1988). The amount and diversity of data that have to be handled and analysed can be staggering, especially in large-scale operational programmes. Thus each programme requires a properly developed data-flow structure, e.g. from field teams via field sub-offices to programme headquarters, and an efficient data-analysis unit. A programme website is very useful; it permits all concerned to have access anytime to the raw and analysed data.

Comprehensive field data recording sheets are indispensable, and must be adapted to the biological characteristics of each target species and to the needs of each programme. Data sheets should include all information relevant to a proper data analysis, e.g. details on animals screened, details on the composition of trap samples, geo-referenced trap deployment sites, baits, types of traps, etc. Using electronic data collectors, and transmitting data to computers at programme headquarters via e-mail, facsimile, or HF radio, even if rather sophisticated compared with traditional paper methods, permit rapid and efficient data collection and compilation (Bouyer et al., this volume). In addition, field-monitoring data should be complemented with climatic data from remote automated weather stations in the target area.

Using identical sampling periods, standardized sampling procedures, and uniform compilation methods ensure homogeneous data sets; they greatly facilitate the analysis and interpretation of the data (Box 4). The Gregorian year with 365 days can be divided into equal periods for data collection and compilation, e.g. in the tsetse programme in Zanzibar, traps were checked 1-5 times per week, depending on the importance of the area, but all of the data were compiled on a weekly basis (Vreysen et al. 2000). Data can be compiled using EXCEL spreadsheets or an ACCESS-based database; the latter is more appropriate for large amounts of data, and allows easy incorporation into most GIS. Particularly useful are databases which have been developed to manage the field data of specific pest control programmes, and which can promote the standardization of data reporting and analysis on a regional scale, e.g. the Disease and Vector Integrated Database (DAVID) (Robinson 2001).

The frequency of analysing the data is related to the regularity of sampling and compilation of the data, but is usually done every 1-3 months; however, if the insect has a high reproductive rate, it will be done much more frequently. In the analysis of trap catches, indices, such as daily or weekly catch per trap, and the proportion of positive traps, can be used. However, Clift and Meats (1998) showed that the proportion of positive traps is not a good indicator in the early stages of a programme, since the proportion of positive traps is only slightly reduced when the catch per trap declines from 10 to 1 . Standard statistical methods such as analysis of variance in a randomized block design (with fixed time units as blocks) can, after proper transformation of the data, be used for the temporal and spatial comparison of data (Sokal and Rolf 1995). 


\section{CONCLUSIONS}

The importance of reliable monitoring data before, during, and after the release of sterile insects cannot be overstated. In spite of the availability of efficient "direct" and "indirect" surveillance methods suitable for a variety of target species, the monitoring component in operational programmes is too often neglected. Consequently, programme management and decision-making are based more on established protocols, availability of financial resources, and political inspiration rather than on sound scientific principles.

Programmes that release sterile insects are inherently complex, with many critical components in the production process (aimed at delivering high-quality insects), methods of handling and transport, and dispersal procedures. The multifaceted nature of these programmes also implies that the probability of problems occurring is higher than in conventional pest control programmes.

\section{Box 4. Concept of Reference Sites for Monitoring or Surveys}

Notwithstanding the importance of sound and robust monitoring activities in an AW-IPM programme, funds are needed to deploy each sampling device. Monitoring activities should be planned as a compromise between cost-efficiency and providing adequate and sufficient data. AW-IPM programmes tend to be implemented over large geographical areas, and monitoring (or surveying) in detail the entire area is not feasible, practical or cost-effective. Selecting reference (or fixed) monitoring sites, representative of a certain area, is a useful approach to efficiently monitor or survey large geographical areas (Leak et al. 2009).

Depending on the size of the target area, this is divided into Universal Transverse Mercator (UTM) squares, e.g. $5 \times 5 \mathrm{~km}$ or $10 \times 10 \mathrm{~km}$, and each UTM grid square is characterized by parameters that are important to the distribution of the pest, i.e. vegetation, land use, land cover, hydrology, soil type, altitude, etc. Pending the availability of these specific data layers, GIS can facilitate the characterization of the grid squares (Bouyer et al., this volume). Therefore each grid square has a certain number of classes, which are of relevance to the abundance and distribution of the pest. After considering accessibility, logistics, personnel, etc., a reference monitoring site can be selected for each class of each grid, and a certain number of sampling devices deployed in each reference monitoring site, which will then be representative for that class in that specific grid square.

This approach was applied to develop and implement an efficient sampling strategy for the collection of entomological baseline data in the tsetse project in the Southern Rift Valley of Ethiopia (Vreysen 2000) and in the Niayes of Senegal (Bouyer et al. 2010).

In the case of Ethiopia, about 15-18 trapping sites were selected in each UTM square (total of 105 squares, each $10 \times 10 \mathrm{~km}$ ) to sample the wild fly populations during four surveys within 1 year. Accurate data on the spatial and temporal differences of the tsetse populations were collected with limited resources over a large geographical area (more than $10000 \mathrm{~km}^{2}$ ) using carefully selected trapping sites in representative areas (Vreysen et al. 1999b; Vreysen 2000).

In the case of Senegal, a 5 x $5 \mathrm{~km}$ grid overlaying the entire target area (286 cells) was developed to facilitate the field sampling procedures. During preliminary surveys, a phytosociological census achieved a supervised classification of the vegetation in addition to some entomological data collected in the various habitats. This enabled an assessment of the suitability of the habitat to harbour the tsetse fly G. p. gambiensis in the area, denoted as wet areas since the suitability was correlated with the presence of ground water at the end of the dry season. All these wet areas were identified in each of the grids and georeferenced for the deployment of tsetse traps (Bouyer et al. 2010). 


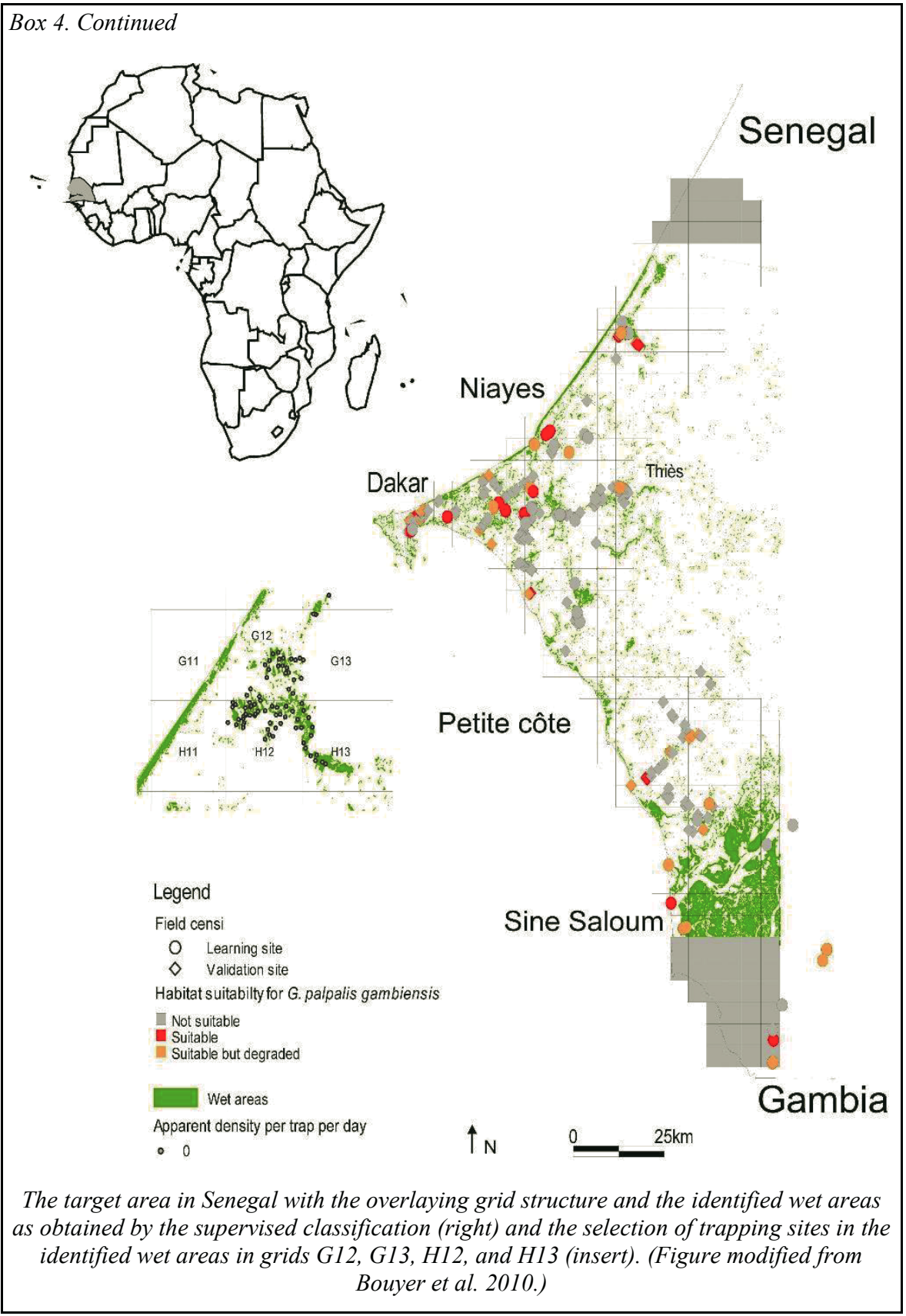


Only the availability of reliable field data can: (1) provide clear evidence that observed programme progress is due to released sterile insects and other measures applied to suppress the pest population, (2) identify the causes of problems and suggest possible solutions, and (3) increase the efficiency of the programmes by more strategic deployment of sterile insects. It is acknowledged that monitoring methods are often time-consuming, labour-intensive, and even laborious, but in many instances the financial losses, resulting from inefficient management decisions made without the benefit of reliable field data, outweigh the costs of monitoring activities.

Several shortcomings in implementing the monitoring activities of operational programmes have been pointed out. The need for more standardization, research, and development to improve several aspects of monitoring the field component of these programmes has been highlighted. Examples of these aspects are: (1) development of guidelines to standardize sampling procedures (trap types for specific species, lures and attractants, trap deployment, trap densities, etc.) (FAO/IAEA 2018, 2020a, b), (2) refinement and development of more efficient lure and trapping systems, (3) better understanding of insect ecology, in relation to insect densities, aggregation patterns, and dispersal characteristics, (4) research on visual markers in the sperm of sterile males, (5) better methods of measuring induced sterility, and (6) simple statistical probability methods, which can easily be applied by field entomologists, to assess the absence of a target species.

\section{REFERENCES}

Alford, A. R., and P. J. Silk. 1983. Effect of pheromone-releaser distribution and release rate on the mating success of spruce budworm (Lepidoptera: Tortricidae). Journal of Economic Entomology 76: 774-778.

Barclay, H. J., and J. W. Hargrove. 2005. Probability models to facilitate a declaration of pest-free status, with special reference to tsetse (Diptera: Glossinidae). Bulletin of Entomological Research 95: 1-11. https://doi.org/10.1079/BER2004331

Baylis, M., and C. O. Nambiro. 1993. The responses of Glossina pallidipes and G. longipennis (Diptera: Glossinidae) to odour-baited traps and targets at Galana Ranch, south-eastern Kenya. Bulletin of Entomological Research 83: 145-151.

Blanco, C. A., O. Perera, J. D. Ray, E. Taliercio, and L. Williams III. 2006. Incorporation of rhodamine $\mathrm{B}$ into male tobacco budworm moths Heliothis virescens to use as a marker for mating studies. Journal of Insect Science 6: 5. https://doi.org/10.1673/1536-2442(2006)6[1:IORBIM]2.0.CO;2

Bloem, K. A., and S. Bloem. 2000. SIT for codling moth eradication in British Columbia, Canada, pp. 207-214. In K. H. Tan (ed.), Proceedings: Area-Wide Control of Fruit Flies and Other Insect Pests. International Conference on Area-Wide Control of Insect Pests, and the $5^{\text {th }}$ International Symposium on Fruit Flies of Economic Importance, 28 May-5 June 1998, Penang, Malaysia. Penerbit Universiti Sains Malaysia, Pulau Pinang, Malaysia.

http://www-naweb.iaea.org/nafa/ipc/public/Area-wide-control_73-229.pdf

Bloem, S., S. D. Hight, J. E. Carpenter, and K. A. Bloem. 2005. Development of the most effective trap to monitor the presence of the cactus moth Cactoblastis cactorum (Lepidoptera: Pyralidae). Florida Entomologist 88(3): 300-306. https://journals.flvc.org/flaent/article/view/75442

Bouyer, J., T. Balenghien, S. Ravel, L. Vial, I. Sidibé, S. Thévenon, P. Solano, and T. de Meeûs. 2009. Population sizes and dispersal patterns of tsetse flies: rolling on the river? Molecular Ecology 18: 2787 2797. http://onlinelibrary.wiley.com/doi/10.1111/j.1365-294X.2009.04233.x/abstract

Bouyer, J., M. T. Seck, B. Sall, E. Y. Ndiaye, L. Guerrini, and M. J. B. Vreysen. 2010. Stratified entomological sampling in preparation for an area-wide integrated pest management programme: the example of Glossina palpalis gambiensis (Diptera: Glossinidae) in the Niayes of Senegal. Journal of Medical Entomology 47: 543-552. https://doi.org/10.1603/ME09149 
Bouyer, J., A. H. Dicko, G. Cecchi, S. Ravel, L. Guerrini, P. Solano, M. J. B. Vreysen, T. De Meeûs, and R. Lancelot. 2015. Mapping landscape friction to locate isolated tsetse populations that are candidates for elimination. Proceedings of the National Academy of Sciences of the USA 112(47): 1457514580. https://doi.org/10.1073/pnas.1516778112

Brenner, R. J. 1984. Dispersal, mating and oviposition of the screwworm (Diptera: Calliphoridae) in southern Mexico. Annals of the Entomological Society of America 77: 779-788.

Calkins, C. O., A. L. Knight, G. Richardson, and K. A. Bloem. 2000. Area-wide population suppression of codling moth, pp. 215-219. In K. H. Tan (ed.), Proceedings: Area-Wide Control of Fruit Flies and Other Insect Pests. International Conference on Area-Wide Control of Insect Pests, and the $5^{\text {th }}$ International Symposium on Fruit Flies of Economic Importance, 28 May-5 June 1998, Penang, Malaysia. Penerbit Universiti Sains Malaysia, Pulau Pinang, Malaysia. http://www-naweb.iaea.org/nafa/ipc/public/Area-wide-control_73-229.pdf

Carey, J. R. 1982. Demography and population dynamics of the $\bar{M}$. Ecological Modelling 16(2/4): 125-150.

Carpenter, J. E., O. G. Marti, S. L. Wee, and D. M. Suckling. 2009. Cytological attributes of sperm bundles unique to $F_{1}$ progeny of irradiated male Lepidoptera: relevance to sterile insect technique programs. Florida Entomologist 92: 80-86. https://doi.org/10.1653/024.092.0113

Carrieri, M., A. Masetti, A. Albieri, B. Maccagnani, and R. Bellini. 2009. Larvicidal activity and influence of Bacillus thuringiensis var. israelensis on Aedes albopictus oviposition in ovitraps during a two-week check interval protocol. Journal of the American Mosquito Control Association 25(2): 149 156. https://doi.org/10.2987/08-5852.1

Carrieri, M., A. Albieri, P. Angelini, F. Baldacchini, C. Venturelli, S. M. Zeo, and R. Bellini. 2011. Surveillance of the chikungunya vector Aedes albopictus (Skuse) in Emilia-Romagna (northern Italy): organizational and technical aspects of a large scale monitoring system. Journal of Vector Ecology 36: 108-116. https://doi.org/10.1111/j.1948-7134.2011.00147.x

Carrieri, M., A. Albieri, S. Urbanelli, P. Angelini, C. Venturelli, C. Matrangolo, and R. Bellini. 2017. Quality control and data validation procedure in large-scale quantitative monitoring of mosquito density: the case of Aedes albopictus in Emilia-Romagna region, Italy. Pathogens and Global Health 111(2): 83-90. https://doi.org/10.1080/20477724.2017.1292992

Challier, A. 1965. Amélioration de la méthode de détermination de l'âge physiologique des glossines. Bulletin de la Société de Pathologie exotique et de ses Filiales 58: 250-259.

Chinellato, F., M. Simonato, A. Battisti, M. Faccoli, S. Hardwick, and D. M. Suckling. 2013. Smart-traps combined with molecular on-site detection to monitor Monochamus spp. and associated pine wood nematode, pp. 23-25. In T. Schröder (ed.), Pine Wilt Disease Conference, Braunschweig, Germany.

Clift, A. D., and A. Meats. 1998. The relation of 'percentage of positive traps' to the negative binominal distribution and to progress in the eradication of Bactrocera papayae Drew and Hancock (Diptera: Tephritidae) in northern Queensland. Genetic Applications in Entomology 28: 61-64.

Colvin, J., and G. Gibson. 1992. Host-seeking behavior and management of tsetse. Annual Review of Entomology 37: 21-40. https://doi.org/10.1146/annurev.en.37.010192.000321

Cuisance, D., and J. Itard. 1973. Comportement de mâles stériles de Glossina tachinoides Westw. lâches dans les conditions naturelles, environs de fort Lamy (Tchad). I. Transport, lâchers, rythme d'activité, action sur la population sauvage. Revue d'Élevage et de Médecine Vétérinaire des Pays Tropicaux 26: $55-76$.

Curtis, C., and P. Langley. 1982. Sterility induction in tsetse, pp. 169-183. In Proceedings, Symposium: Sterile Insect Technique and Radiation in Insect Control. Food and Agriculture Organization of the United Nations/International Atomic Energy Agency, 29 June-3 July 1981, Neuherberg, Germany. STI/PUB/595. IAEA, Vienna, Austria. http://www-naweb.iaea.org/nafa/ipc/public/SIT-RadiationProceedings-1982.pdf

Davis, R. B., B. G. Hightower, D. A. Alley, J. E. Turner, and E. Lopez. 1968. Releases of sterile screwworm flies in northern Veracruz, Mexico, measured by recovery of sterile egg masses. Journal of Economic Entomology 61: 96-101.

De Longo, O., A. Colombo, P. Gomez-Riera, and A. Bartolucci. 2000. The use of massive SIT for the control of the medfly, Ceratitis capitata (Wied.), strain SEIB 6-96, in Mendoza, Argentina, pp. 351359. In K. H. Tan (ed.), Proceedings: Area-Wide Control of Fruit Flies and Other Insect Pests. International Conference on Area-Wide Control of Insect Pests, and the $5^{\text {th }}$ International Symposium on Fruit Flies of Economic Importance, 28 May-5 June 1998, Penang, Malaysia. Penerbit Universiti Sains Malaysia, Pulau Pinang, Malaysia.

http://www-naweb.iaea.org/nafa/ipc/public/Area-wide-control_351-490.pdf 
De Meeûs, T., S. Ravel, J. B. Rayaisse, F. Courtin, and P. Solano. 2012. Understanding local population genetics of tsetse: the case of an isolated population of Glossina palpalis gambiensis in Burkina Faso. Infection, Genetics and Evolution 12: 1229-1234.

https://doi.org/10.1016/j.meegid.2012.04.005

Dicko, A. H., R. Lancelot, M. T. Seck, L. Guerrini, B. Sall, M. Lo, M. J. B. Vreysen, T. Lefrançois, W. M. Fonta, S. L. Peck, and J. Bouyer. 2014. Using species distribution models to optimize vector control in the framework of the tsetse eradication campaign in Senegal. Proceedings of the National Academy of Sciences of the USA 111(28): 10149-10154. https://doi.org/10.1073/pnas.1407773111

Dransfield, R. D., R. Brightwell, J. Onah, and C. J. Okolo. 1982. Population dynamics of Glossina morsitans submorsitans Newstead and G. tachinoides (Diptera: Glossinidae) in sub-Sudan savannah in Northern Nigeria. 1. Sampling methodology for adults and seasonal changes in numbers caught in different vegetation types. Bulletin of Entomological Research 72: 175-192.

Dyck, V. A., S. H. Graham, and K. A. Bloem. 1993. Implementation of the sterile insect release programme to eradicate the codling moth Cydia pomonella (L.) (Lepidoptera: Olethreutidae) in British Columbia, Canada, pp. 285-297. In Proceedings: Management of Insect Pests: Nuclear and Related Molecular and Genetic Techniques. FAO/IAEA International Symposium, 19-23 October 1992, Vienna, Austria. STI/PUB/909. IAEA, Vienna, Austria.

https://www.iaea.org/publications/3782/management-of-insect-pests-nuclear-and-related-molecularand-genetic-techniques

Dyck, V. A., H. Pan, S. S. Kassim, F. W. Suleiman, W. A. Mussa, K. M. Saleh, K. G. Juma, P. A. Mkonyi, W. G. Holland, B. J. M. van der Eerden, and R. H. Dwinger. 2000. Monitoring the incidence of trypanosomosis in cattle during the release of sterilized tsetse flies on Unguja Island, Zanzibar. Revue d'Élevage et de Médecine Vétérinaire des Pays Tropicaux 53: 239-243. http://revues.cirad.fr/index.php/REMVT/article/view/9718/9712

Enkerlin, W. 2001. Economics of area-wide fruit fly sterile insect technique programs, pp. 83-106. In Proceedings, Seminar, Madeira Med: Sterile Insect Technique as an Environmentally Friendly and Effective Insect Control System. Região Autónoma da Madeira and European Union, 12-13 November 1999, Funchal, Madeira. Madeira Regional Direction of Agriculture, Portugal.

(FAO) Food and Agriculture Organization of the United Nations. 1992. The New World screwworm eradication programme, North Africa (1988-1992). FAO, Rome, Italy. https://www.iaea.org/sites/default/files/18/03/ipc-screwworm-libya-1992-full.pdf

(FAO) Food and Agriculture Organization of the United Nations. 2016. Establishment of pest free areas for fruit flies (Tephritidae). International Standards for Phytosanitary Measures (ISPM) 26, International Plant Protection Convention (IPPC). FAO, Rome, Italy.

https://www.ippc.int/static/media/files/publication/en/2016/01/ISPM_26_2015_WithAnn3_En_201512-22_Reformatted.pdf

(FAO/IAEA) Food and Agriculture Organization of the United Nations/International Atomic Energy Agency. 2018. Trapping guidelines for area-wide fruit fly programmes, Second edition. W. R. Enkerlin and J. Reyes-Flores (eds.). Rome, Italy. 65 pp. https://www.iaea.org/sites/default/files/trapping-guideline.pdf

(FAO/IAEA) Food and Agriculture Organization of the United Nations/International Atomic Energy Agency. 2019. Fruit sampling guidelines for area-wide fruit fly programmes. W. R. Enkerlin, J. Reyes and G. Ortiz (eds.), FAO, Vienna, Austria. 38 pp. https://www.iaea.org/sites/default/files/ca5716en.pdf

(FAO/IAEA) Food and Agriculture Organization of the United Nations/International Atomic Energy Agency. 2020a. Mosquito handling, transport, release and male trapping methods. FAO/IAEA Coordinated Research Project. http://www-naweb.iaea.org/nafa/ipc/crp/ipc-mosquito-handling.html

(FAO/IAEA) Food and Agriculture Organization of the United Nations/International Atomic Energy Agency. 2020b. Guidelines for mark-release-recapture procedures of Aedes mosquitoes. Version 1.0. J. Bouyer, F. Balestrino, N. Culbert, H. Yamada and R. Argilés (eds.), FAO/IAEA, Vienna, Austria. 22 pp. https://www.iaea.org/sites/default/files/guidelines-for-mrr-aedes_v1.0.pdf

(FAO/IAEA/USDA) Food and Agriculture Organization of the United Nations/International Atomic Energy Agency/United States Department of Agriculture. 2019. Product quality control for sterile mass-reared and released tephritid fruit flies. Version 7.0. IAEA, Vienna, Austria. 148 pp. https://www.iaea.org/sites/default/files/qcv7.pdf

(FAO/OIEA) Food and Agriculture Organization of the United Nations/Organismo Internacional de Energía Atómica. 2018. Manual para diferenciar moscas de Anastrepha ludens (Loew) silvestres y criadas de cepa normal ("bi-sexual”) y cepa sexada genéticamente (Tapachula-7), irradiadas y sin 
irradiar. J. C. Guillén Aguilar, L. López Muñoz, E. F. López Villalobos, y D. N. Soto García. FAO, Roma, Italia. 95 pp. http://www-naweb.iaea.org/nafa/ipc/public/Manual-para-diferenciar-moscas.pdf

Flores, S., E. Gómez-Escobar, P. Liedo, J. Toledo, and P. Montoya. 2017. Density estimation and optimal sterile-to-wild ratio to induce sterility in Anastrepha obliqua populations. Entomologia Experimentalis et Applicata 164: 284-290. http://onlinelibrary.wiley.com/doi/10.1111/eea.12580/full

Fried, M. 1971. Determination of sterile-insect competitiveness. Journal of Economic Entomology 64: $869-872$.

Glasgow, J. P., and J. R. Welch. 1962. Long-term fluctuations in numbers of the tsetse fly Glossina swynnertoni Austen. Bulletin of Entomological Research 53: 129-137.

Gouteux, J. P. 1987. Ecodistribution de Glossina palpalis palpalis (Rob.-Desv.) en secteur préforestier de Côte-d'Ivoire. Sexe, rythmes ovaro-utérins et utilisation de l'espace. Acta Oecologica 8: 27-38.

Green, C. H. 1994. Bait methods for tsetse fly control. Advances in Parasitology 34: 229-291.

Hagan, H. R. 1951. Embryology of viviparous insects. Ronald Press Company, New York, NY, USA.

Hagler, J. R., and C. G. Jackson. 2001. Methods for marking insects: current techniques and future prospects. Annual Review of Entomology 46: 511-543. https://doi.org/10.1146/annurev.ento.46.1.511

Haisch, A. 1970. Some observations on decreased vitality of irradiated Mediterranean fruit fly, pp. 71-75. In Proceedings, Panel: Sterile-Male Technique for Control of Fruit Flies. Joint FAO/IAEA Division of Atomic Energy in Food and Agriculture, 1-5 September 1969, Vienna, Austria. STI/PUB/276. IAEA, Vienna, Austria. http://www-naweb.iaea.org/nafa/ipc/public/ipc-sterile_male-technique-control-fruit-flies.pdf

Hall, M. J. R. 1995. Trapping the flies that cause myiasis: their responses to host-stimuli. Annals of Tropical Medicine and Parasitology 89: 333-357.

Hall, M. J. R., and R. Wall. 1995. Myiasis of humans and domestic animals. Advances in Parasitology 35: $257-334$.

Hamer, G. L., D. J. Donovan, R. Hood-Nowotny, M. G. Kaufman, T. L. Goldberg, and E. D. Walker. 2012. Evaluation of a stable isotope method to mark naturally-breeding larval mosquitoes for adult dispersal studies. Journal of Medical Entomology 49: 61-70. https://doi.org/10.1603/ME11076

Hargrove, J. W. 2005. Extinction probabilities and times to extinction for populations of tsetse flies Glossina spp. (Diptera: Glossinidae) subjected to various control measures. Bulletin of Entomological Research 95: 13-21. https://doi.org/10.1079/BER2004335

Hargrove, J. W., and G. A. Vale. 1980. Catches of Glossina morsitans morsitans Westwood and $G$. pallidipes Austen (Diptera: Glossinidae) in odour-baited traps in riverine and deciduous woodlands in the Zambesi valley of Zimbabwe. Bulletin of Entomological Research 70: 571-578.

Harley, J. M. B. 1965. Seasonal and diurnal variations in physiological age and trypanosome infection rate of females of Glossina pallidipes Austen, G. palpalis fuscipes Newstead and G. brevipalpis Newstead. Bulletin of Entomological Research 56: 595-614.

Helinski, M. E. H., R. C. Hood-Nowotny, L. Mayr, and B. G. J. Knols. 2007. Stable isotope-mass spectrometric determination of semen transfer in malaria mosquitoes. Journal of Experimental Biology 210: 1266-1274. http://dx.doi.org/10.1242/jeb.002642

Hendrichs, J., G. Franz, and P. Rendón. 1995. Increased effectiveness and applicability of the sterile insect technique through male-only releases for control of Mediterranean fruit flies during fruiting seasons. Journal of Applied Entomology 119: 371-377.

Hightower, B. G., A. L. Adams, and D. A. Alley. 1965. Dispersal of released irradiated laboratory-reared screw-worm flies. Journal of Economic Entomology 58: 373-374.

Hood-Nowotny, R., L. Mayr, A. Islam, A. Robinson, and C. Caceres. 2009. Routine isotope marking for the Mediterranean fruit fly (Diptera: Tephritidae). Journal of Economic Entomology 102: 941-947. https://doi.org/10.1603/029.102.0312

Hood-Nowotny, R., M. Watzka, L. Mayr, S. Mekonnen, B. Kapitano, and A. Parker. 2011. Intrinsic and synthetic stable isotope marking of tsetse flies. Journal of Insect Science 11: 79. https://doi.org/10.1673/031.011.7901

Hood-Nowotny, R., A. Harari, R. K. Seth, S. L. Wee, D. E. Conlong, D. M. Suckling, B. Woods, K. Lebdi-Grissa, G. Simmons, and J. E. Carpenter. 2016a. Stable isotope markers differentiate between mass-reared and wild Lepidoptera in sterile insect technique programs. Florida Entomologist 99 (S1): 166-176. http://journals.fcla.edu/flaent/article/view/88498 
Hood-Nowotny, R., L. Mayr, N. Saad, R. K. Seth, G. Davidowitz, and G. Simmons. 2016b. Towards incorporating insect isotope analysis using cavity ring-down spectroscopy into area-wide insect pest management programs. Florida Entomologist 99 (S1): 177-184.

http://journals.fcla.edu/flaent/article/view/88499

Hutt, R. B. 1979. Codling moth (Laspeyresia pomonella) (Lepidoptera: Olethreutidae): improving field performance of mass-reared males. Canadian Entomologist 111: 661-664.

(IAEA) International Atomic Energy Agency. 1999. Development of female medfly attractant systems for trapping and sterility assessment. Proceedings, Final research co-ordination meeting, Joint FAO/IAEA Division of Nuclear Techniques in Food and Agriculture, 28 May-1 June 1998, Penang, Malaysia. IAEA-TECDOC-1099. IAEA, Vienna, Austria.

(IAEA) International Atomic Energy Agency. 2009. Manual for the use of stable isotopes in entomology. IAEA, Vienna, Austria. http://www-naweb.iaea.org/nafa/ipc/public/IAEA_SI_Hi-Res_final.pdf

Itô, Y., and H. Kakinohana. 1995. Eradication of the melon fly (Diptera: Tephritidae) from the Ryukyu archipelago with the sterile insect technique: possible reasons for its success, pp. 215-229. In The Mediterranean fruit fly in California: defining critical research. University of California, Riverside, CA, USA.

Itô, Y., and J. Koyama. 1982. Eradication of the melon fly: role of population ecology in the successful implementation of the sterile insect release method. Protection Ecology 4: 1-28.

Iwahashi, O. 1977. Eradication of the melon fly, Dacus cucurbitae from Kume Island, Okinawa with the sterile insect release method. Researches in Population Ecology 19: 87-98.

Iwahashi, O., Y. Itô, H. Zukeyama, and Y. Yogi. 1976. A progress report on the sterile insect releases of the melon fly, Dacus cucurbitae (Diptera: Tephritidae) on Kume Island, Okinawa. Applied Entomology and Zoology 11: 182-193.

Iwahashi, O., Y. Itô, and M. Shiyomi. 1983. A field evaluation of the sexual competitiveness of sterile melon flies, Dacus cucurbitae. Ecological Entomology 8: 43-48.

Jackson, C. H. N. 1939. The analysis of an animal population. Journal of Animal Ecology 8: 234-246.

Jackson, C. H. N. 1946. An artificially isolated generation of tsetse flies. Bulletin of Entomological Research 32: 291-299.

Johnson, B. J., S. N. Mitchell, C. J. Paton, J. Stevenson, K. M. Staunton, N. Snoad, N. Beebe, B. J. White, and S. A. Ritchie. 2017. Use of rhodamine B to mark the body and seminal fluid of male Aedes aegypti for mark-release-recapture experiments and estimating efficacy of sterile male releases. PLOS Neglected Tropical Diseases 11(9): e0005902. https://doi.org/10.1371/journal.pntd.0005902

Juan-Blasco, M., A. Urbaneja, V. San Andrés, P. Castañera, and B. Sabater-Muñoz. 2013. Improving the sterile sperm identification method for its implementation in the area-wide sterile insect technique program against Ceratitis capitata (Diptera: Tephritidae) in Spain. Journal of Economic Entomology 106: 2541-2547. https://doi.org/10.1603/EC13064

Katsoyannos, B. I. 1994. Evaluation of Mediterranean fruit-fly traps for use in sterile-insect-technique programmes. Journal of Applied Entomology 118: 442-452.

Katsoyannos, B. I., N. T. Papadopoulos, N. A. Kouloussis, R. Heath, and J. Hendrichs. 1999. Method of assessing the fertility of wild Ceratitis capitata (Diptera: Tephritidae) females for use in sterile insect technique programs. Journal of Economic Entomology 92: 590-597.

Knight, A. L. 2000. Monitoring codling moth (Lepidoptera: Tortricidae) with passive interception traps in sex pheromone-treated apple orchards. Journal of Economic Entomology 93: 1744-1751.

Krafsur, E. S., and L. Garcia. 1978. Responses of the screwworm, Cochliomyia hominivorax, to two sterile males release methods in south Texas, 1975-1976. Journal of Medical Entomology 14: 687-697.

Krafsur, E. S., and B. G. Hightower. 1979. Field tests of sterile screwworm flies, Cochliomyia hominivorax (Diptera: Calliphoridae), against natural populations in three coastal areas of Mexico. Journal of Medical Entomology 16: 33-42.

Krafsur, E. S., B. G. Hightower, and L. Leira. 1979. A longitudinal study of screwworm populations, Cochliomyia hominivorax (Diptera: Calliphoridae), in northern Veracruz, Mexico. Journal of Medical Entomology 16: 470-481.

Krafsur, E. S., B. G. Hightower, and M. Vargas. 1980. Responses of screwworm (Diptera: Calliphoridae) populations to sterile male challenge in Veracruz. Journal of Medical Entomology 17: 235-241.

Krafsur, E. S., C. J. Whitten, and J. E. Novy. 1987. Screwworm eradication in North and Central America. Parasitology Today 3: 131-137. 
LaChance, L. E. 1979. Genetic changes affecting the success and economy of the sterile insect release method, pp. 8-18. In M. A. Hoy and J. J. McKelvey (eds.), Genetics in relation to insect management. Rockefeller Foundation, New York, NY, USA.

LaChance, L. E., and S. B. Bruns. 1963. Oogenesis and radio-sensitivity in Cochliomyia hominivorax (Diptera: Calliphoridae). Biological Bulletin 124: 65-83.

LaChance, L. E., C. H. Schmidt, and R. C. Bushland. 1967. Radiation induced sterilisation, pp. 147196. In W. W. Kilgore and R. L. Doutt (eds.), Pest control: biological, physical and selected chemical methods. Academic Press, New York. NY, USA.

Lance, D. R., and D. B. Gates. 1994. Sensitivity of detection trapping systems for Mediterranean fruit flies (Diptera: Tephritidae) in southern California. Journal of Economic Entomology 87: 1377-1383.

Langley, P., M. J. Hall, and T. Felton. 1988. Determining the age of tsetse flies Glossina spp. (Diptera: Glossinidae): an appraisal of the pteridine fluorescence technique. Bulletin of Entomological Research 78: 387-395.

Laveissière, C., and P. Grébaut. 1990. Recherches sur les pièges à glossines (Diptera: Glossinidae). Mise au point d'un modèle économique: le piège "Vavoua". Tropical Medicine and Parasitology 41: 185192.

Leak, S. G. A., D. Ejigu, and M. J. B. Vreysen. 2009. Collection of entomological baseline data for tsetse area-wide integrated pest management programmes. FAO Animal Production and Health Guidelines No. 1. FAO, Rome, Italy. http://www.fao.org/docrep/011/i0535e/i0535e00.htm

Lehane, M. J., and T. S. Mail. 1985. Determining the age of adult male and female Glossina morsitans morsitans using a new technique. Ecological Entomology 10: 219-224.

Liebhold, A. M., J. S. Elkinton, G. Zhou, M. E. Hohn, R. E. Rossi, G. H. Boettner, C. W. Boettner, C. Burnham, and M. L. McManus. 1995. Regional correlation of gypsy moth (Lepidoptera: Lymantriidae) defoliation with counts of egg masses, pupae and male moths. Environmental Entomology 24: 193-203.

Liedo, P., and J. R. Carey. 1996. Demography of fruit flies and implications to action programs, pp. 299308. In B. A. McPheron and G. J. Steck (eds.), Fruit fly pests. A world assessment of their biology and management. St. Lucie Press, Delray Beach, FL, USA.

Light, D. M., A. L. Knight, C. A. Henrick, D. Rajapaska, B. Lindgren, J. C. Dickens, K. M. Reynolds, R. G. Buttery, G. Merrill, J. Roitman, and B. C. Campbell. 2001. A pear derived kairomone with pheromonal potency that attracts male and female codling moth, Cydia pomonella (L.). Naturwissenschaften 88: 333-338.

Lindquist, D. A., M. Abusowa, and M. J. R. Hall. 1992. The New World screwworm fly in Libya: a review of its introduction and eradication. Medical and Veterinary Entomology 6: 2-8.

Lühken, R., W. P. Pfitzner, J. Börstler, R. Garms, K. Huber, N. Schork, S. Steinke, E. Kiel, N. Becker, E. Tannich, and A. Krüger. 2014. Field evaluation of four widely used mosquito traps in Central Europe. Parasites and Vectors 7: 268. https://doi.org/10.1186/1756-3305-7-268

Mastro, V. C., and C. P. Schwalbe. 1988. Status and potential of $F_{1}$ sterility for control of noxious Lepidoptera, pp. 15-40. In Proceedings, Symposium: Modern Insect Control: Nuclear Techniques and Biotechnology. International Atomic Energy Agency/Food and Agriculture Organization of the United Nations, 16-20 November 1987, Vienna, Austria. STI/PUB/763. IAEA, Vienna, Austria.

http://www-naweb.iaea.org/nafa/ipc/public/ipc-Modern-Insect-Control.pdf

Mayer, D. G., M. G. Atzeni, M. A. Stuart, K. A. Anaman, and D. G. Butler. 1998. Mating competitiveness of irradiated flies for screwworm fly eradication campaigns. Preventive Veterinary Medicine 36: 1-9.

McArdle, B. H. 1990. When are rare species not there? Oikos 57: 276-277.

McBrien, H. L., and G. J. R. Judd. 1996. A Teflon ${ }^{\circledR}$-walled mating table for assessing pheromone-based mating disruption. Journal of the Entomological Society of British Columbia 93: 121-125.

McDermotte, J. J. 2000. Evidence required for establishing the absence of tsetse and trypanosomosis associated with tsetse eradication programmes, pp. 155-164. In Animal trypanosomosis: diagnosis and epidemiology. Report, FAO/IAEA Co-ordinated Research Programme on the use of immunoassay methods for improved diagnosis of trypanosomosis and monitoring tsetse and trypanosomosis control programmes. IAEA, Vienna, Austria.

McInnis, D. O. 1993. Size differences between normal and irradiated sperm heads in mated female Mediterranean fruit flies (Diptera: Tephritidae). Annals of the Entomological Society of America 86: 305-308. 
McInnis, D. O., S. Tam, C. Grace, and D. Miyashita. 1994. Population suppression and sterility rates induced by variable sex ratio, sterile insect releases of Ceratitis capitata (Diptera: Tephritidae). Annals of the Entomological Society of America 87: 231-240.

McInnis, D. O., J. Hendrichs, T. Shelly, W. Barr, K. Hoffman, R. Rodriguez, D. R. Lance, K. Bloem, D. M. Suckling, W. Enkerlin, P. Gomes, and K. H. Tan. 2017. Can polyphagous invasive tephritid pest populations escape detection for years under favorable climatic and host conditions? American Entomologist 63: 8999. https://doi.org/10.1093/ae/tmx038

Meats, A. 1996. Demographic analysis of sterile insect trials with the Queensland fruit fly Bactrocera tryoni (Froggatt) (Diptera: Tephritidae). Genetic Applications in Entomology 27: 2-12.

Meixner, M. D., B. A. McPheron, J. G. Silva, G. E. Gasparich, and W. S. Sheppard. 2002. The Mediterranean fruit fly in California: evidence for multiple introductions and persistent populations based on microsatellite and mitochondrial DNA variability. Molecular Ecology 11: 891-899. http://onlinelibrary.wiley.com/doi/10.1046/j.1365-294X.2002.01488.x/abstract

Mendoza, J. P., F. E. Dowell, A. B. Broce, J. E. Throne, R. A. Wirtz, F. Xie, J. A. Fabrick, and J. A. Baker. 2002. Chronological age-grading of house flies by using near-infrared spectroscopy. Journal of Medical Entomology 39: 499-508. https://doi.org/10.1603/0022-2585-39.3.499

Midgarden, D., O. Ovalle, N. D. Epsky, H. Puche, P. E. Kendra, P. Rendon, and R. R. Heath. 2004. Capture of Mediterranean fruit flies (Diptera: Tephritidae) in dry traps baited with a food-based attractant and Jackson traps baited with trimedlure during sterile male release in Guatemala. Journal of Economic Entomology 97: 2137-2143. https://doi.org/10.1093/jee/97.6.2137

Miranda, M. A., R. Alonso, and A. Alemany. 2001. Field evaluation of medfly (Dipt., Tephritidae) female attractants in a Mediterranean agrosystem (Balearic Islands, Spain). Journal of Applied Entomology 125: 333-339. http://onlinelibrary.wiley.com/doi/10.1046/j.1439-0418.2001.00548.x/full

Molyneux, D. H., F. Evens, and A. M. V. Van der Vloedt. 1982. Review of problems of vectorial capacity of Glossina in relation to sterile male release programmes. Annales de la Societé belge de Médecine tropicale 62: 95-102.

Nakamori, H., and M. Shiga. 1993. Characteristics of hot spots of melon fly, Bactrocera (Dacus) cucurbitae Coquillett (Diptera: Tephritidae) in sterile fly release areas on Okinawa Island. Japanese Journal of Applied Entomology and Zoology 37: 123-128.

Niyazi, N., C. Caceres, A. Delprat, V. Wornoayporn, E. Ramirez Santos, G. Franz, and A. S. Robinson. 2005. Genetics and mating competitiveness of Ceratitis capitata (Diptera: Tephritidae) strains carrying the marker Sergeant, $\mathrm{Sr}^{2}$. Annals of the Entomological Society of America 98: 119125. https://doi.org/10.1603/0013-8746(2005)098[0119:GAMCOC]2.0.CO;2

Oladunmade, M. A., U. Feldmann, W. Takken, S. O. Tenabe, H. J. Hamann, J. Onah, L. Dengwat, A. M. V. Van der Vloedt, and R. E. Gingrich. 1990. Eradication of Glossina palpalis palpalis (Robineau-Desvoidy) (Diptera: Glossinidae) from agropastoral land in central Nigeria by means of the sterile insect technique, pp. 5-23. In Proceedings: Sterile Insect Technique for Tsetse Control and Eradication. Joint FAO/IAEA Division of Nuclear Techniques in Food and Agriculture, Final Research Co-ordination Meeting, 6-10 June 1988, Vom, Nigeria. STI/PUB/830. IAEA, Vienna, Austria. http://www-naweb.iaea.org/nafa/ipc/public/ipc-tsetse-eradication-sit-1990.pdf

Otieno, L. H., P. Onyango, and E. Mpanga. 1990. Effect of insecticide spraying operations on a Glossina pallidipes Austen (Diptera: Glossinidae) population and on animal trypanosomiasis in Lambwe valley, western Kenya. Discovery and Innovation 2: 97-102.

Pagabeleguem, S., G. Gimonneau, M. T. Seck, M. J. B. Vreysen, B. Sall, J. B. Rayaissé, I. Sidibé, J. Bouyer, and S. Ravel. 2016. A molecular method to discriminate between mass-reared sterile and wild tsetse flies during eradication programmes that have a sterile insect technique component. PLOS Neglected Tropical Diseases 10(2): e0004491. https://doi.org/10.1371/journal.pntd.0004491

Parker, F. D., and J. B. Welch. 1991. Alternative to sentinel animals for collecting egg masses from wild females of screwworm (Diptera: Calliphoridae). Journal of Economic Entomology 84: 1476-1479. https://www.ncbi.nlm.nih.gov/pubmed/1744297

Parman, D. C. 1945. Effect of weather on Cochliomyia americana and a review of methods and economic applications of the study. Journal of Economic Entomology 38: 66-76.

Peterson, R. D., D. O. McInnis, C. J. Whitten, and J. R. Coppedge. 1980. Dispersal and distribution of ground released screwworms Cochliomyia hominivorax (Diptera: Calliphoridae). United States Department of Agriculture, Animal and Plant Health Inspection Service 91-57: 1-11.

Petrić, D., R. Bellini, E. J. Scholte, L. M. Rakotoarivony, and F. Schaffner. 2014. Monitoring population and environmental parameters of invasive mosquito species in Europe. Parasites and Vectors 7: 187. https://doi.org/10.1186/1756-3305-7-187 
Politzar, H., and D. Cuisance. 1984. An integrated campaign against riverine tsetse, Glossina palpalis gambiensis and Glossina tachinoides, by trapping and the release of sterile males. Insect Science and its Application 5: 439-442.

Proverbs, M. D. 1974. Ecology and sterile release programs, the measurement of relevant population processes before and during release and assessment of results, pp. 201-223. In R. Pal and M. J. Whitten (eds.), The use of genetics in insect control. Elsevier, Amsterdam, The Netherlands.

Proverbs, M. D., D. M. Logan, and B. E. Carty. 1973. Some biological observations related to codling moth control by the sterility principle, pp. 149-163. In Proceedings, Panel: Computer Models and Application of the Sterile-Male Technique. Joint FAO/IAEA Division of Atomic Energy in Food and Agriculture, 13-17 December 1971, Vienna, Austria. STI/PUB/340. IAEA, Vienna, Austria. http://www-naweb.iaea.org/nafa/ipc/public/El_Computer_Models.pdf

RapidAIM. 2018. Real-time alerts of the presence and location of fruit fly. http://rapidaim.io/

Reed, J. M. 1996. Using statistical probability to increase confidence of inferring species extinction. Conservation Biology 10: 1283-1285.

Rempoulakis, P., G. Taret, I. Ul Haq, V. Wornayporn, S. Ahmad, U. Sto Tomas, T. Damalage, K. Gembinsky, G. Franz, C. Cáceres, and M. J. B. Vreysen. 2016. Evaluation of quality production parameters and mating behavior of novel genetic sexing strains of the Mediterranean fruit fly Ceratitis capitata (Wiedemann) (Diptera: Tephritidae). PLOS ONE 11(6): e0157679. https://doi.org/10.1371/journal.pone.0157679

Rendón, P., D. McInnis, D. Lance, and J. Stewart. 2004. Medfly (Diptera: Tephritidae) genetic sexing: large-scale field comparison of males-only and bisexual sterile fly releases in Guatemala. Journal of Economic Entomology 97: 1547-1553. https://doi.org/10.1603/0022-0493-97.5.1547

Reyes, J., A. Villaseñor, A. Schwarz, and J. Hendrichs. 1988. Organization of medfly eradication campaigns, pp. 107-116. In Proceedings, Symposium: Modern Insect Control: Nuclear Techniques and Biotechnology. International Atomic Energy Agency/Food and Agriculture Organization of the United Nations, 16-20 November 1987, Vienna, Austria. STI/PUB/763. IAEA, Vienna, Austria. http://www-naweb.iaea.org/nafa/ipc/public/ipc-Modern-Insect-Control.pdf

Riedl, H., J. F. Howell, P. S. McNally, and P. H. Westigard. 1986. Codling moth management: use and standardisation of pheromone trapping systems. University of California Bulletin 1918. University of California, USA.

Ritchie, S. A. 1984. The production of Aedes aegypti by a weekly ovitrap survey. Mosquito News 44(1): 77-79. https://www.biodiversitylibrary.org/content/part/JAMCA/MN_V44_N1_P077-79.pdf

Robinson, D. E., J. W. Snow, and G. Grant. 2000. The use of the sterile insect technique (SIT) to eradicate the screwworm fly, Cochliomyia hominivorax, from Jamaica, pp. 213-216. In Proceedings: Utilisation of Natural Products in Developing Countries: Trends and Needs. International Symposium, 10-14 July 2000, Kingston, Jamaica.

Robinson, T. 2001. DAVID: a disease and vector integrated data base. Newsletter on Integrated Control of Pathogenic Trypanosomes and their Vectors 3: 13.

Rogers, D. J. 1978. Metabolic strategies of male and female tsetse (Diptera: Glossinidae) in the field. Bulletin of Entomological Research 68: 63-77.

Rogers, D. J., and S. E. Randolph. 1986. Distribution and abundance of tsetse flies. Journal of Animal Ecology 55: 1007-1025.

Ryan, L., D. H. Molyneux, and F. A. S. Kuzoe. 1980. Differences in rate of wing-fray between Glossina species. Topenmedizin und Parasitologie 31: 111-116.

Saleh, K. M., W. A. Mussa, K. G. Juma, and M. J. B. Vreysen. 1999. Eradication of Glossina austeni from the island of Unguja confirmed; results of 2 years of post-eradication monitoring activities, pp. 231-238. In Proceedings: $25^{\text {th }}$ meeting of the International Scientific Council for Trypanosomiasis Research and Control, 27 September-1 October 1999, Mombasa, Kenya. OAU/IBAR, Nairobi, Kenya.

San Andrés, V., A. Urbaneja, B. Sabater-Muñoz, and P. Castañera. 2007. A novel molecular approach to assess mating success of sterile Ceratitis capitata (Diptera: Tephritidae) males in sterile insect technique programs. Journal of Economic Entomology 100: 1444-1449. https://doi.org/10.1093/jee/100.4.1444

Saunders, D. S. 1960. The ovulation cycle in Glossina morsitans Westwood (Diptera: Muscidae) and a possible method for age determination for female flies by the examination of their ovaries. Transactions of the Royal Entomological Society of London 112: 211-238.

Saunders, D. S. 1972. The effect of starvation on the length of the interlarval period in the tsetse fly Glossina morsitans orientalis Vanderplank. Journal of Entomology 46: 197-202. 
Scolari, F., M. F. Schetelig, S. Bertin, A. R. Malacrida, G. Gasperi, and E. A. Wimmer. 2008. Fluorescent sperm marking to improve the fight against the pest insect Ceratitis capitata (Wiedemann; Diptera: Tephritidae). New Biotechnology 25: 76-84. https://doi.org/10.1016/j.nbt.2008.02.001

Shaver, T. N., and H. E. Brown. 1993. Evaluation of pheromone to disrupt mating of Eoreuma loftini (Lepidoptera: Pyralidae) in sugarcane. Journal of Economic Entomology 86: 377-381.

Shiga, M. 1991. Future prospects of eradication of fruit flies. pp. 126136. In K. Kawasaki, O. Iwahashi and K. Y. Kaneshiro (eds.), Proceedings of the International Symposium on the Biology and Control of Fruit Flies, 24 September 1991. Ginowan, Okinawa, Japan.

Silva, J. G., M. D. Meixner, B. A. McPheron, G. J. Steck, and W. S Sheppard. 2003. Recent Mediterranean fruit fly (Diptera: Tephritidae) infestations in Florida - a genetic perspective. Journal of Economic Entomology 96: 1711-1718. https://doi.org/10.1093/jee/96.6.1711

Simmons, G. S., , D. M. Suckling, J. E. Carpenter M. F. Addison, V. A. Dyck, and M. J. B. Vreysen. 2010. Improved quality management to enhance the efficacy of the sterile insect technique for lepidopteran pests. Journal of Applied Entomology 134: 261-273. http://onlinelibrary.wiley.com/doi/10.1111/j.1439-0418.2009.01438.x/abstract

Snow, J. W., W. W. Cantello, and M. C. Bowman. 1969. Distribution of the corn earworm on St. Croix, US Virgin Islands and its relation to suppression programs. Journal of Economic Entomology 62: 606611.

Snow, J. W., J. R. Raulston, and F. S. Guillot. 1976. Mating tables: a method of studying the mating and competitive behaviour of Lepidoptera and Diptera in the field. Annals of the Entomological Society of America 69: 751-752.

Sokal, R. R., and F. J. Rohlf. 1995. Biometry. The principles and practice of statistics in biological research, $3^{\text {rd }}$ ed. W. H. Freeman, New York, NY, USA.

Solow, A. R. 1993. Inferring extinction in a declining population. Journal of Mathematical Biology 32: 79-82.

Southwood, T. R. E. 1978. Ecological methods, with particular reference to the study of insect populations. Chapman and Hall, London, UK.

Spradbery, J. P. 1994. Screwworm fly: a tale of two species. Agricultural Zoology Reviews 6: 1-62.

Staten, R. T., R. W. Rosander, and D. F. Keaveny. 1993. Genetic control of cotton insects. The pink bollworm as a working programme, pp. 269-283. In Proceedings: Management of Insect Pests: Nuclear and Related Molecular and Genetic Techniques. FAO/IAEA International Symposium, 19-23 October 1992, Vienna, Austria. STI/PUB/909. IAEA, Vienna, Austria.

https://www.iaea.org/publications/3782/management-of-insect-pests-nuclear-and-related-molecularand-genetic-techniques

Tan, K. H. 1993. Ecohormones for the management of fruit fly pests. Understanding plant-fruit flypredator interrelationships, pp. 495-503. In Proceedings: Management of Insect Pests: Nuclear and Related Molecular and Genetic Techniques. FAO/IAEA International Symposium, 19-23 October 1992, Vienna, Austria. STI/PUB/909. IAEA, Vienna, Austria.

https://www.iaea.org/publications/3782/management-of-insect-pests-nuclear-and-related-molecularand-genetic-techniques

Thomas, D. B. 1993. Behavioral aspects of screwworm ecology. Journal of the Kansas Entomological Society 66: 13-30.

Thomas, D. B., and A. C. Chen. 1990. Age distribution of adult female screwworms (Diptera: Calliphoridae) captured on sentinel animals in the coastal lowlands of Guatemala. Journal of Economic Entomology 83: 1422-1429.

Thomas, D. B., and R. L. Mangan. 1989. Oviposition and wound-visiting behavior of the screwworm fly, Cochliomyia hominivorax (Diptera: Calliphoridae). Annals of the Entomological Society of America 82: 526-534.

Tobe, S. S., and P. A. Langley. 1978. Reproductive physiology of Glossina. Annual Review of Entomology 23: 283-307. https://doi.org/10.1146/annurev.en.23.010178.001435

Tomic-Carruthers, N., R. Mangan, and R. Carruthers. 2002. Age estimation of Mexican fruit fly (Diptera: Tephritidae) based on accumulation of pterins. Journal of Economic Entomology 95: 13191325. https://doi.org/10.1603/0022-0493-95.6.1319

Turner, D. A. 1987. The population ecology of Glossina pallidipes Austen (Diptera: Glossinidae) in the Lambwe Valley, Kenya. 1. Feeding behaviour and activity patterns. Bull. Entom. Res. 77: 317-333.

Turner, D. A., and R. Brightwell. 1986. An evaluation of a sequential aerial spraying operation against Glossina pallidipes Austen (Diptera: Glossinidae) in the Lambwe Valley of Kenya: aspects of postspray recovery and evidence of natural population regulation. Bull. of Entom. Research 76: 331-349. 
Tzanakakis, M. E. 1974. Current status and prospects of applying the sterile-insect release method against Dacus oleae, pp. 109-115. In Proceedings, Panel: The Sterile-Insect Technique and its Field Applications. Joint FAO/IAEA Division of Atomic Energy in Food and Agriculture, 13-17 November 1972, Vienna, Austria. STI/PUB/364. IAEA, Vienna, Austria.

http://www-naweb.iaea.org/nafa/ipc/public/ipc-sterile-insect-technique-field-aplns-1974.pdf

Vale, G. A., and R. J. Phelps. 1978. Sampling problems with tsetse flies (Diptera: Glossinidae). Journal of Applied Ecology 15: 715-726.

Van der Vloedt, A. M. V., and H. Barnor. 1984. The effects of ionising radiation on tsetse biology. Their relevance to entomological monitoring during integrated control programmes using the sterile insect technique. Insect Science and its Application 5: 431-437.

Van der Vloedt, A. M. V., M. Taher, and S. O. Tenabe. 1978. Effect of gamma radiation on the tsetse fly Glossina palpalis palpalis (Rob.-Desv.) (Diptera, Glossinidae) with observations on the reproductive biology. International Journal of Applied Radiation and Isotopes 29: 713-716.

Van der Vloedt, A. M. V., D. A. T. Baldry, H. Politzar, H. Kulzer, and D. Cuisance. 1980. Experimental helicopter applications of decamethrin followed by release of sterile males for the control of riverine vectors of trypanosomiasis in Upper Volta. Insect Science and its Application 1: 105-112.

van de Straat, B., A. Hiscox, W. Takken, and T. R. Burkot. 2019. Evaluating synthetic odours and trap designs for monitoring Anopheles farauti in Queensland, Australia. Malaria Journal 18: 299. https://doi.org/10.1186/s12936-019-2923-7

Venette, R. C., R. D. Moon, and W. D. Hutchison. 2002. Strategies and statistics of sampling for rare individuals. Ann. Rev. Entom. 47: 143-174. https://doi.org/10.1146/annurev.ento.47.091201.145147

Villaseñor, A., J. Carrillo, J. Zavala, J. Stewart, C. Lira, and J. Reyes. 2000. Current progress in the medfly program Mexico-Guatemala, pp. 361-368. In K. H. Tan (ed.), Proceedings: Area-Wide Control of Fruit Flies and Other Insect Pests. International Conference on Area-Wide Control of Insect Pests, and the $5^{\text {th }}$ International Symposium on Fruit Flies of Economic Importance, 28 May-5 June 1998, Penang, Malaysia. Penerbit Universiti Sains Malaysia, Pulau Pinang, Malaysia. http://www-naweb.iaea.org/nafa/ipc/public/Area-wide-control_351-490.pdf

Vreysen, M. J. B. 1995. Radiation induced sterility to control tsetse flies. The effect of ionising radiation and hybridisation on tsetse biology and the use of the sterile insect technique in integrated tsetse control. PhD dissertation, Wageningen Agricultural University, Wageningen, The Netherlands.

Vreysen, M. J. B. 2000. Southern Rift Valley tsetse eradication programme - analysis of the entomological base-line data collected between October 1998 and September 1999. IAEA, Vienna.

Vreysen, M. J. B. 2001. Principles of area-wide integrated tsetse fly control using the sterile insect technique. Médecine Tropicale 61: 397-411.

Vreysen, M. J. B., and I. S. Khamis. 1999. Notes on the ecology of a natural Glossina austeni (Diptera: Glossinidae) population in the Jozani forest, Unguja Island of Zanzibar. Insect Science and its Application 19: 99-108. https://doi.org/10.1017/S1742758400019354

Vreysen, M. J. B., and K. M. Saleh. 2001. Long-term sampling of gamma sterilised male Glossina austeni (Diptera: Glossinidae) with sticky panels on Unguja Island (Zanzibar). Acta Tropica 80: 29-37. https://doi.org/10.1016/S0001-706X(01)00143-7

Vreysen, M. J. B., and A. M. V. Van der Vloedt. 1992. The use of gamma sterilised Glossina austeni females as sentinel insects for entomological monitoring in tsetse control programmes. Revue d'Élevage et de Médecine Vétérinaire des Pays Tropicaux 45: 303-309.

Vreysen, M. J. B., A. M. V. Van der Vloedt, and H. Barnor. 1996. Comparative gamma radiation sensitivity of Glossina tachinoides Westw., Glossina fuscipes fuscipes Newst. and Glossina brevipalpis Newst. (Diptera, Glossinidae). International Journal of Radiation Biology 69: 67-74.

Vreysen, M. J. B., K. M. Saleh, I. S. Khamis, and F. Mramba. 1999a. An evaluation of insecticideimpregnated screens against Glossina austeni (Diptera: Glossinidae) on Unguja Island of Zanzibar. Insect Science and its Application 19: 75-84. https://doi.org/10.1017/S1742758400016611

Vreysen, M. J. B., A. Mebrate, M. Menjeta, B. Bancha, G. Woldeyes, K. Musie, K. Bekele, and G. Aboset. 1999b. The distribution and relative abundance of tsetse flies in the Southern Rift Valley of Ethiopia: preliminary survey results, pp. 202-213. In Proceedings: $25^{\text {th }}$ meeting of the Inter. Sci. Council for Trypan. Res. and Control, 27 September-1 October 1999, Mombasa. OAU/IBAR, Nairobi, Kenya.

Vreysen, M. J. B., K. M. Saleh, M. Y. Ali, A. M. Abdullah, Z. R. Zhu, K. G. Juma, V. A. Dyck, A. R. Msangi, P. A. Mkonyi, and H. U. Feldmann. 2000. Glossina austeni (Diptera: Glossinidae) eradicated on the island of Unguja, Zanzibar, using the sterile insect technique. Journal of Economic Entomology 93: 123-135. https://doi.org/10.1603/0022-0493-93.1.123 
Vreysen, M. J. B., J. Gerardo-Abaya, and J. P. Cayol. 2007. Lessons from area-wide integrated pest management (AW-IPM) programmes with an SIT component: an FAO/IAEA perspective, pp. 723-744. In M. J. B. Vreysen, A. S. Robinson and J. Hendrichs (eds.), Area-wide control of insect pests. From research to field implementation. Springer, Dordrecht, The Netherlands. http://www-naweb.iaea.org/nafa/ipc/public/Area-Wide-Control-Insect-Pests-book.pdf

Vreysen, M. J. B., K. M. Saleh, R. Lancelot, and J. Bouyer. 2011. Factory tsetse flies must behave like wild flies: a prerequisite for the sterile insect technique. PLOS Neglected Tropical Diseases 5(2): e907. https://doi.org/10.1371/journal.pntd.0000907

Vreysen, M. J. B., W. Klassen, and J. E. Carpenter. 2016. Overview of technological advances toward greater efficiency and efficacy in sterile insect-inherited sterility programs against moth pests. Florida Entomologist 99 (S1): 1-12. http://journals.fcla.edu/flaent/article/view/88480

Wall, R. 1990. Ovarian ageing of tsetse flies (Diptera: Glossinidae) — interspecific differences. Bulletin of Entomological Research 80: 85-89.

Wall, R., P. A. Langley, J. Stevens, and G. M. Clarke. 1990. Age determination in the old-screwworm fly, Chrysomya bezziana by pteridine fluorescence. Journal of Insect Physiology 36: 213-218.

Walters, M. L., R. T. Staten, and R. C. Roberson. 2000. Pink bollworm integrated management using sterile insects under field trial conditions, Imperial Valley, California, pp. 201-206. In K. H. Tan (ed.), Proceedings: Area-Wide Control of Fruit Flies and Other Insect Pests. International Conference on Area-Wide Control of Insect Pests, and the $5^{\text {th }}$ International Symposium on Fruit Flies of Economic Importance, 28 May-5 June 1998, Penang, Malaysia. Penerbit Universiti Sains Malaysia, Pulau Pinang, Malaysia. http://www-naweb.iaea.org/nafa/ipc/public/Area-wide-control_73-229.pdf

Waterhouse, D. F., L. E. LaChance, and M. J. Whitten. 1976. Use of autocidal methods, pp. 637-659. In C. B. Huffaker and P. S. Messenger (eds.), Theory and practice of biological control. Academic Press, New York, NY, USA.

Wee, S. L. 2016. Effects of conspecific herbivory and mating status on host searching and oviposition behavior of Plutella xylostella (Lepidoptera: Plutellidae) in relation to its host, Brassica oleracea (Brassicales: Brassicaceae). Florida Entomologist 99 (S1): 159-165. http://journals.fcla.edu/flaent/article/view/88497

Wee, S. L., D. M. Suckling, and A. M. Barrington. 2011. Feasibility study on cytological sperm bundle assessment of $\mathrm{F}_{1}$ progeny of irradiated male painted apple moth (Teia anartoides Walker; Lepidoptera: Lymantriidae) for the sterile insect technique. Australian Journal of Entomology 50: 269-275. http://onlinelibrary.wiley.com/doi/10.1111/j.1440-6055.2011.00815.x/full

Wee, S. L., H. W. Oh, and K. C. Park. 2016. Antennal sensillum morphology and electrophysiological responses of olfactory receptor neurons in trichoid sensilla of the diamondback moth (Lepidoptera: Plutellidae). Florida Entomologist 99 (S1): 146-158. http://journals.fcla.edu/flaent/article/view/88496

Williams, B. G., R. Dransfield, and R. Brightwell. 1990a. Monitoring tsetse fly populations. 1. The intrinsic variability of Glossina pallidipes at Nguruman. Med. and Veterinary Entomology 4: 167-179.

Williams, B. G., R. Brightwell, and R. Dransfield. 1990b. Monitoring tsetse fly populations. 2. The effect of climate on trap catches of Glossina pallidipes. Med. and Veterinary Entomology 4: 181-193.

Williams, B. G., R. Dransfield, and R. Brightwell. 1992. The control of tsetse flies in relation to fly movement and trapping efficiency. Journal of Applied Entomology 29: 163-179.

Wong, T. T. Y., L. C. Whitehand, R. M. Kobayashi, K. Ohinata, N. Tanaka, and E. J. Harris. 1982. Mediterranean fruit fly: dispersal of wild and irradiated and untreated laboratory-reared males. Environmental Entomology 11: 339-343.

Wong, T. T. Y., R. M. Kobayashi, and D. O. McInnis. 1986. Mediterranean fruit fly (Diptera: Tephritidae): methods of assessing the effectiveness of sterile insect releases. Journal of Economic Entomology 79: 1501-1506.

Wyss, J. H. 2000. Screw-worm eradication in the Americas - overview, pp. 79-86. In K. H. Tan (ed.), Proceedings: Area-Wide Control of Fruit Flies and Other Insect Pests. International Conference on Area-Wide Control of Insect Pests, and the $5^{\text {th }}$ International Symposium on Fruit Flies of Economic Importance, 28 May-5 June 1998, Penang, Malaysia. Penerbit Universiti Sains Malaysia, Pulau Pinang, Malaysia. http://www-naweb.iaea.org/nafa/ipc/public/Area-wide-control_73-229.pdf

Yamagishi, M., H. Kakinohana, H. Kuba, T. Kohama, Y. Nakamoto, Y. Sokei, and K. Kinjo. 1993. Eradication of the melon fly from Okinawa, Japan, by means of the sterile insect technique, pp. 49-60. In Proceedings: Management of Insect Pests: Nuclear and Related Molecular and Genetic Techniques. FAO/IAEA International Symposium, 19-23 October 1992, Vienna, Austria. STI/PUB/909. IAEA, Vienna, Austria. https://www.iaea.org/publications/3782/management-of-insect-pests-nuclear-andrelated-molecular-and-genetic-techniques 